\title{
Using an integrative taxonomic approach to delimit a sibling species, Mycetomoellerius mikromelanos sp. nov. (Formicidae: Attini: Attina)
}

\author{
Cody Raul Cardenas ${ }^{\text {Corresp., } 1}$, Amy Luo ${ }^{2}$, Tappey H Jones ${ }^{3}$, Ted Schultz ${ }^{4}$, Rachelle Adams ${ }^{\text {Corresp. 1, } 4}$ \\ 1 Department of Evolution, Ecology and Organismal Biology, The Ohio State University, Columbus, Ohio, United States of America \\ 2 Department of Ecology \& Evolutionary Biology, University of Tennessee Knoxville, Knoxville, Tennessee, United States of America \\ 3 Department of Chemistry, Virginia Military Institute, Lexington, Virginia, United States of America \\ 4 Department of Entomology, National Museum of Natural History, Smithsonian Institution, Washington, District of Colombia, United States of America \\ Corresponding Authors: Cody Raul Cardenas, Rachelle Adams \\ Email address: cardenas.61@buckeyemail.osu.edu, adams.1970@osu.edu
}

The fungus-growing ant Mycetomoellerius (previously Trachymyrmex) zeteki (Weber 1940) has been the focus of a wide range of studies examining symbiotic partners, garden pathogens, mating frequencies, and genomics. This is in part due to the ease of collecting colonies from creek embankments and its high abundance in the Panama Canal region. The original description was based on samples collected on Barro Colorado Island ( $\mathrm{BCl})$, Panama. However, most subsequent studies have sampled populations on the mainland 15 $\mathrm{km}$ southeast of $\mathrm{BCl}$. Herein we show that two sibling ant species live in sympatry on the mainland: Mycetomoellerius mikromelanos sp. nov. Cardenas, Schultz, \& Adams and $M$. zeteki. This distinction was originally based on behavioral differences of workers in the field and on queen morphology (M. mikromelanos workers and queens are smaller and black while those of $M$. zeteki are larger and red). Authors frequently refer to either species as "M. cf. zeteki," indicating uncertainty about identity. We used an integrative taxonomic approach to resolve this, examining worker behavior, chemical profiles of worker volatiles, molecular markers, and morphology of all castes. For the latter, we used conventional taxonomic indicators from nine measurements, six extrapolated indices, and morphological characters. We document a new observation of a Diapriinae (Hymenoptera: Diapriidae) parasitoid wasp parasitizing M. zeteki. Finally, we discuss the importance of vouchering in dependable, accessible museum collections and provide a table of previously published papers to clarify the usage of the name $T$. zeteki. We found that most reports of $M$. zeteki or $M$. cf. zeteki-including a genome-actually refer to the new species M. mikromelanos. 


\section{Using an integrative taxonomic approach to delimit a sibling}

2 species, Mycetomoellerius mikromelanos sp. nov.

3 (Formicidae: Attini: Attina)

4

5 Cody Raul Cardenas ${ }^{1}$, Amy R. Luo², Tappey H. Jones ${ }^{3}$, Ted R. Schultz ${ }^{4}$, and Rachelle M.M.

6 Adams $^{1,4}$

$7 \quad{ }^{1}$ Department of Evolution, Ecology and Organismal Biology, The Ohio State University,

8 Columbus, Ohio, United States of America

$9 \quad 2$ Department of Ecology \& Evolutionary Biology, University of Tennessee Knoxville,

10 Knoxville, Tennessee, United States of America

$11{ }^{3}$ Department of Chemistry, Virginia Military Institute, Lexington, Virginia, United States of

12 America

$13{ }^{4}$ Department of Entomology, National Museum of Natural History, Smithsonian Institution, 14 Washington, District of Colombia, United States of America

15 Corresponding Authors:

16 Cody Raul Cardenas \& Rachelle MM Adams

17 Email address: cardenas.61@buckeyemail.osu.edu (CRC) adams.1970@osu.edu (RMMA). 


\section{Abstract}

19 The fungus-growing ant Mycetomoellerius (previously Trachymyrmex) zeteki (Weber 1940) has

20 been the focus of a wide range of studies examining symbiotic partners, garden pathogens, 21 mating frequencies, and genomics. This is in part due to the ease of collecting colonies from 22 creek embankments and its high abundance in the Panama Canal region. The original description 23 was based on samples collected on Barro Colorado Island (BCI), Panama. However, most 24 subsequent studies have sampled populations on the mainland $15 \mathrm{~km}$ southeast of BCI. Herein 25 we show that two sibling ant species live in sympatry on the mainland: Mycetomoellerius 26 mikromelanos sp. nov. Cardenas, Schultz, \& Adams and M. zeteki. This distinction was 27 originally based on behavioral differences of workers in the field and on queen morphology $(M$. 28 mikromelanos workers and queens are smaller and black while those of M. zeteki are larger and 29 red). Authors frequently refer to either species as " $M$. cf. zeteki," indicating uncertainty about identity. We used an integrative taxonomic approach to resolve this, examining worker behavior, chemical profiles of worker volatiles, molecular markers, and morphology of all castes. For the latter, we used conventional taxonomic indicators from nine measurements, six extrapolated indices, and morphological characters. We document a new observation of a Diapriinae (Hymenoptera: Diapriidae) parasitoid wasp parasitizing M. zeteki. Finally, we discuss the importance of vouchering in dependable, accessible museum collections and provide a table of previously published papers to clarify the usage of the name T. zeteki. We found that most reports of $M$. zeteki or $M$. cf. zeteki-including a genome - actually refer to the new species $M$. mikromelanos. 
39

40

41

42

43

44

45

46

47

48

49

50

51

52

53

54

55

56

57

58

59

60

61

62

63

64

65

66

67

68

69

70

71

72

73

74

75

76

77

78

\section{Introduction}

Fungus-growing ants (Hymenoptera: Formicidae: Attini: Attina; Ward et al., 2015), referred to as "attine" ants, cultivate mutualistic fungus gardens using sophisticated agricultural practices (Weber, 1958a). This clade of 240 extant described species has been tending and feeding cultivated fungi for ca. 60 million years (Branstetter et al., 2017). Because fungus-growing ants have been focal taxa of studies in evolutionary biology, including mating systems (Baer \& Boomsma, 2004; Boomsma, 2007), symbiotic networks (Mueller, Rehner \& Schultz, 1998; Currie, Mueller \& Malloch, 1999), social parasitism (Adams et al., 2013), host fidelity (Mehdiabadi et al., 2012), and genome evolution (Nygaard et al., 2016), it is imperative that the taxonomy of attine ants accurately reflects their evolutionary history. Diverse studies indicate the existence of many undescribed species (Schultz \& Meier, 1995; Schultz, Bekkevold \& Boomsma, 1998; Rabeling et al., 2007; Schultz \& Brady, 2008; Mehdiabadi et al., 2012; Ješovnik et al., 2013; Sosa-Calvo et al., 2018; Solomon et al., 2019) and alpha-taxonomic work has been steadily carried out by many taxonomists (Mayhé-Nunes \& Brandão, 2002, 2005, 2007; Sosa-Calvo \& Schultz, 2010; Ješovnik et al., 2013; Rabeling et al., 2015; Ješovnik \& Schultz, 2017; Sosa-Calvo et al., 2017, 2018). In fact an average of 2.4 new attine species have been described per year from 1995 to 2019 (Table S1, e.g., Schultz et al., 2002; Ješovnik et al., 2013; Sánchez-Peña et al., 2017; Sosa-Calvo et al., 2018; Cristiano et al., 2020).

Taxonomists have informally split the attines into lower and higher fungus-growing ants based on varying systems of obligate fungus-farming agriculture (Schultz \& Brady, 2008; Branstetter et al., 2017). The lower attines cultivate a diversity of fungal cultivar lineages, while the higher attines generally cultivate more closely related lineages of fungal species including

Leucoagaricus gongylophorus (Möller) Singer 1986. The most derived and familiar higher attine genera consist of the leaf-cutting ants, Atta Fabricius 1804, Acromyrmex Mayr 1865, and

Amoimyrmex Cristiano, Cardoso \& Sandoval 2020 which largely cut fresh plant material for their gardens. However, the other higher attine genera consist of Sericomyrmex Mayr 1865,

Trachymyrmex Forel 1893, Xerolitor Sosa-Calvo, Schultz, Jesovnik, Dahan, \& Rabeling, 2018, Mycetomoellerius Solomon, Rabeling, Sosa-Calvo, \& Schultz 2019, and Paratrachymyrmex

Solomon, Rabeling, Sosa-Calvo, \& Schultz 2019. These non-leaf-cutting higher attines, referred to as higher attines hereafter, are phylogenetically intermediate between the lower-attine and leaf-cutting ants (Brandão \& Mayhé-Nunes, 2007).

Higher attine ants share natural history traits with both the lower attines and leaf-cutting ants. Similar to leaf-cutting ants, some higher attines have also been observed cutting fresh plant material for their gardens (Weber, 1972; Schultz \& Meier, 1995; Leal \& Oliveira, 2000; MayhéNunes \& Brandão, 2005; Brandão \& Mayhé-Nunes, 2007). Otherwise, much like lower attines, higher attines typically harvest fallen flowers, fruits, leaves, small twigs, seeds, and caterpillar frass (Lizidatti, 2006; De Fine Licht \& Boomsma, 2010; Ronque, Feitosa \& Oliveira, 2019). Unlike lower-attine workers that are typically monomorphic, workers in Mycetomoellerius, Paratrachymyrmex, and Trachymyrmex tend to be weakly polymorphic (Weber, 1958a; Beshers \& Traniello, 1996; Brandão \& Mayhé-Nunes, 2007; Rabeling et al., 2007). It is this variability in 
79

80

81

82

83

84

85

86

87

88

89

90

91

92

93

94

95

96

97

98

99

100

101

102

103

104

105

106

107

108

109

110

111

112

113

114

115

116

117

worker morphology, coupled with species descriptions based on a few workers (Weber, 1940), sampling bias (see Mueller et al., 2018), and inconsistent voucher deposition that have led to incorrect or incomplete species identifications (Appendix Table S1).

The genus Mycetomoellerius is represented by 31 recognized species, distributed throughout Central and South America. Taxonomic clarity for this and related genera is needed as there are likely multiple new species, including a sister clade to the well-studied species M. zeteki (Weber, 1940; junior synonym M. balboai; see also Solomon et al., 2019). Mycetomoellerius zeteki is abundant and easily collected in the Panama Canal Zone and has been included in a large breadth of work (Appendix Table S1). Notable research includes the discovery and function of actinomycete bacteria in the fungus-growing ants (Currie, Mueller \& Malloch, 1999), description of the evolutionary transition from single to multiple mating in the fungus-growing ants (Villesen et al., 2002), and the reciprocal evolution of ant and fungal genomes in the fungusgrowing ant symbiosis (Nygaard et al., 2016). Despite this attention to its biology, M. zeteki has remained taxonomically ambiguous. For example, in a phylogenetic analysis of actinomycetes bacteria, three samples form a polytomy containing $M$. sp. 'Funnel', an undetermined Mycetomoellerius sp., and M. zeteki sensu stricto (Cafaro \& Currie, 2005). It has been speculated that the current definition of $M$. zeteki may include cryptic species based on behavioral (Adams et al., 2012b), morphological (Adams et al., 2012b), molecular (Solomon et al., 2019), and chemical differences (Adams, Jones \& Jeter, 2010; Adams et al., 2012a).

This uncertainty surrounding $M$. cf. zeteki has ramifications given its significant historical contributions to fungus-growing ant research (Appendix Table S1). To resolve this, we use an integrative approach to clarify the taxonomy of $M$. zeteki by reexamining morphological characters, comparing old and new collections, examining morphometrics, adapting a comparative behavioral method for worker tempo, and chemically analyzing worker volatile compounds. Based on these diverse data, we recognize two species: M. zeteki and Mycetomoellerius mikromelanos sp. nov. Cardenas, Schultz, \& Adams. We provide a diagnosis and description of $M$. mikromelanos sp. nov., describe the $M$. zeteki gyne wings and the morphological characters of M. zeteki males, determine the identity of the published M. zeteki genome, suggest corrections for the misidentification of voucher specimens in published research, and discuss the implications of our improved species-level definitions.

\section{Materials \& Methods}

\section{Samples and collections}

Colonies of $M$. mikromelanos sp. nov. (31 colonies) and M. zeteki (16 colonies) were collected at the start of the wet season in 2017 and 2018 in the Canal Zone of the Republic of Panama (9.12007, -79.7317). Colony collection and fieldwork was approved by The Smithsonian Tropical Research Institute as part of the "Behavioral Ecology and Systematics of the Fungusgrowing Ants and Their Symbionts (\#4056)" project and the Autoridad Nacional del Ambiente y el Mar (Permiso de Colecta Científica 2017: SPO-17-173, 2018: SE/AB-1-18). Samples were collected by excavating only the first (i.e., upper) chamber of the nest to ensure colony survival. 
118 Of those excavated in 2018, 16 of 30 colonies were collected into five-dram vials (BioQuip, Cat. 119 No. 8905, California, United States) and transferred to Petri dishes lined with moist cotton fiber

120 for observations while in Panama. Vouchers of ca. 10 or more workers and fungus gardens from 121 each nest were collected in 95\% EtOH. Live colonies were brought back to The Ohio State 122 University to a United States Department of Agriculture Animal and Plant Health Inspection 123 Service Approved Facility (OSU; Columbus Ohio, USA; APHIS permit P526P-16-02785; 124 facility \#4036), where they were transferred to permanent nest boxes (as in Sosa-Calvo et al., 125 2015). When colonies were excavated, many contained workers, male and female reproductive's. 126 We refer to the winged female reproductive caste as gynes unless otherwise noted. Few actual 127 queens were examined. In nearly all cases, if a gyne or queen was present, there are also workers 128 from the same colony (except one specimen from Jack Longino).

\section{Taxonomy \& Morphometrics}

130

131

132

133

134

135

136

137

138

139

140

141

142

143

144

145

146

147

148

149

150

151

152

153

154

155

156

We used a Wild M-5 microscope equipped with an ocular micrometer to examine specimens for morphological characters that unambiguously separate the two species. We also took morphological measurements of 171 workers $(\mathrm{n}=54 \mathrm{M}$. zeteki, $\mathrm{n}=117$ M. mikromelanos $\mathrm{sp}$. nov.), 53 queens and gynes ( $\mathrm{n}=28 \mathrm{M}$. zeteki, $\mathrm{n}=25 \mathrm{M}$. mikromelanos $\mathrm{sp}$. nov.), and 43 males ( $\mathrm{n}$ = 22 M. zeteki, $\mathrm{n}=21 \mathrm{M}$. mikromelanos sp. nov.) using standard morphometrics (Table 1). We included two synonymized $M$. balboai syntypes ('cotypes') and one additional specimen identified as M. balboai. Including this junior synonym of M. zeteki (Weber, 1958b) was necessary to confirm that $M$. mikromelanos is not M. balboai. Upon confirmation, these samples were included as $M$. zeteki in further analyses. Terminology for the temple and malar areas follows that of Boudinot et al. (2013) and for sculpturing that of Harris (1979). Type and voucher specimens of material examined are deposited at the United States National Museum (USNM), Museum of Zoology of the University of São Paulo (MZSP), Smithsonian Tropical Research Institute (STRI), and The Ohio State University Museum of Biological Diversity Triplehorn Insect Collection (OSUC).

The electronic version of this article in Portable Document Format (PDF) will represent a published work according to the International Commission on Zoological Nomenclature (ICZN), and hence the new names contained in the electronic version are effectively published under that Code from the electronic edition alone. This published work and the nomenclatural acts it contains have been registered in ZooBank, the online registration system for the ICZN. The ZooBank LSIDs (Life Science Identifiers) can be resolved and the associated information viewed through any standard web browser by appending the LSID to the prefix http://zoobank.org/. The LSID for this publication is: urn:lsid:zoobank.org:pub:737E04E5-5A8F-48F6-BE32-

ADC1028927B6. The online version of this work is archived and available from the following digital repositories: PeerJ, PubMed Central and CLOCKSS.

We partitioned specimens by caste and tested the assumption of normality for each morphometric character with a Shapiro-Wilks test. We used a Welch's t-test for normally distributed and a Wilcoxon Rank Sum test for non-normally distributed variables to test the null 
157 hypothesis of equal means and differences in range between both species. In the Wilcoxon Rank

158 Sum Test there were ties in the data, so exact p-values could not be calculated for all castes. Both

159 the normality testing and difference of means was performed in the base R package 'stats' ( $R$

160 Core Team, 2017). To reduce the risk of Type I error, only measurements with a Bonferroni

161 corrected P-value $(\mathrm{p}<0.003)$ were included.

162 With our retained variables, we performed non-metric multidimensional scaling (NMDS) with

163 the vegan R package, using the 'metaMDS' function (Oksanen et al., 2019). This function

164 calculates the Bray-Curtis distances, applies a square root transformation, and scales the distance

165 measures down to $\mathrm{k}$ dimensions. We set $\mathrm{k}=2$ and searched for a solution with 1,000 random

166 starts (see McCune \& Grace, 2002; Glon et al., 2019; Oksanen et al., 2019). We subsequently

167 produced a diagnostic Shepard plot with the 'stressplot' command from vegan. We considered

168 our reduced dimensions acceptable if our transformed data reasonably fit the regression of the

169 Shepard plot and if stress scores were $<0.20$ (McCune \& Grace, 2002). We generated NMDS

170 plots with characters plotted as vectors and $95 \%$ confidence ellipses for each species.

171 Behavioral Assay

172 We adapted the novel environment assay (Chapman et al., 2011) to examine the tempo, i.e., 173 activity level, of workers of M. zeteki and M. mikromelanos sp. nov. We subsampled four 174 colonies of each species with five trials per colony. Single workers were selected from the 175 foraging chamber and placed in the center of a $9 \mathrm{~cm}$ Petri dish lined with $1 \mathrm{~cm}^{2}$ grid paper. The 176 ant was immediately covered with one quarter of a $4.5 \mathrm{~cm}$ weigh boat (referred to as "refuge" 177 hereafter). Five-minute trials were recorded with a Sony DCR-PC109 camera, digitized from the 178 cassette tape, and scored using Solomon Coder (Péter, 2017). We measured (1) time to initially 179 emerge from the refuge, (2) number of squares the ant entered, and (3) time spent under the 180 refuge after the initial emergence. To analyze the change in tempo over the trial, we produced a 181 ratio of squares entered to time spent entering squares (i.e., not under the refuge): New Squares / 182 (300 s - Time to Exit Refuge - Time Under Refuge - Time on Refuge $)=$ Tempo.

183 To test whether tempo differed between species we used a generalized linear mixed model 184 (GLMM) with the 'Ime4' package (Bates et al., 2015) in R (R Core Team, 2017). This 185 experiment included multiple workers from the same colony, which are not independent from 186 one another. To account for the blocked design (i.e., multiple data points from the same colony), 187 we included the workers' colony of origin as a random effect in the model. We compared a linear 188 mixed model and multiple GLMMs using gaussian and gamma distribution families with the log, 189 identity, and inverse link functions. To confirm the fit of the model, we first checked the 190 normality of the residuals using a QQ-plot and Shapiro-Wilk test. We then checked for linearity 191 and homoscedasticity by plotting the residuals and fitted values.

192 Phylogenetic analysis

193 We used sequence data published in Solomon et al., (2019; available on Dryad DOI:

194 10.5061/dryad.2p7r771) to confirm the identity of the published genome (Nygaard et al., 2016).

Peer] reviewing PDF | (2020:12:56021:1:1:NEW 8 May 2021) 
195 We used sequences of M. zeteki, M. mikromelanos sp. nov. (listed as Mycetomoellerius n. sp. 196 RMMA in Solomon et al., 2019; Table S2), and M. turrifex (Wheeler, 1903) from the dataset of 197 Solomon et al. (2019) and aligned them in Geneious (version R9; Biomatters Limited, Auckland, 198 New Zealand). We used BLAST with blastn and megablast (Altschul et al., 1990; Zhang et al., 199 2000; Morgulis et al., 2008) to identify quality gene regions in the published genome (Nygaard 200 et al., 2016; GenBank accession: GCA_001594055.1). The gene for COI was removed from the 201 analysis because COI data were missing for a subset of individuals in the data of Solomon et al. 202 (2019). Megablast found no alignments and blastn found multiple scaffolds with high query

203

204

205

206

207

208

209

210

211

212

213

214

215

216

217

218

219

220

221

222

223

224

225

226

227

228

229

230

231

232

233 cover (see Results and Table S3). In Geneious, we mapped our samples to the identified reference genome scaffolds and trimmed the areas of the scaffold that did not align. Once aligned, we concatenated our data into a multi-locus dataset with SequenceMatrix 1.8 (Vaidya, Lohman \& Meier, 2011) for phylogenetic analysis. The four genes used are elongation factor 1-

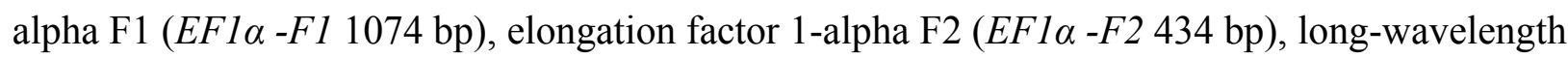
rhodopsin ( $L w R h 455 \mathrm{bp}$ ), and wingless (WG $702 \mathrm{bp}$ ).

For our phylogenetic analysis, we used ModelFinder (Kalyaanamoorthy et al., 2017) in IQTREE (version 1.6.10; Nguyen et al., 2015) to determine the best evolutionary model for each gene. The partitions with the most similar and likely models were merged in IQ-TREE and used to construct a maximum-likelihood phylogeny with M. turrifex as the outgroup and 10,000 ultrafast bootstraps (UFboot2; Hoang et al., 2018). Our resulting consensus tree was annotated in FigTree (version 1.4.3; Rambaut, 2016) and edited in Adobe Illustrator.

\section{Chemical analysis}

Volatile compounds were extracted from workers (as in Hamilton et al., 2018) sampled from labmaintained colonies of M. mikromelanos sp. nov. ( $\mathrm{n}=6$ colonies) and M. zeteki ( $\mathrm{n}=4$ colonies). Samples of 4-10 individuals per colony were placed in HPLC grade methanol solvent. Whole ants from the same colony, or trisected ants (head, thorax, gaster), were placed in separate glass vials with $40-100 \mu \mathrm{L}$ of solvent. Trisections were used to identify where the most abundant compounds were found and whole specimen extractions confirmed the presence of the compounds. Tools used for trisections were rinsed with ethanol, methanol, and pentane between trisection to prevent cross-contamination. Samples were stored at $-20^{\circ} \mathrm{C}$ until analysis by gaschromatography mass-spectrometry (GC-MS). Reported compounds were found in at least trace amounts in two or more extracts of workers of the same species.

Samples of extracts were analyzed at the Virginia Military Institute with gas chromatographymass spectrometry (GC-MS; as in Hamilton et al., 2018) using a Shimadzu QP-2010 GC-MS equipped with an RTX-5, $30 \mathrm{~m} \times 0.25 \mathrm{~mm}$ i.d. column. The carrier gas was helium with a constant flow of $1 \mathrm{ml} / \mathrm{min}$. The temperature program was from 60 to $250{ }^{\circ} \mathrm{C}$ changing $10{ }^{\circ} \mathrm{C} / \mathrm{min}$ and held at the upper temperature for $20 \mathrm{~min}$. The mass spectrometer was operated in EI mode at $70 \mathrm{eV}$, and scanning was set to 40 to $450 \mathrm{AMU}$ at $1.5 \mathrm{scans} / \mathrm{s}$. Peaks on chromatograms were identified by database search (NIST Mass Spectral Data base, V.2, US Department of Commerce, Gaithersburg, MD), published literature spectra, and by direct comparison with 
234 commercially available authentic samples. We standardized our resulting compounds for 235 comparison. For each sample, ratios from the chromatogram peaks were converted to proportions 236 and visualized in Adobe Illustrator.

237

238

239

240

241

242

243

244

245

246

\section{Results}

248

249

250

251

252

253

254

255

256

257

258

259

260

261

262

263

264

265

266

267

268

269

270

271

\section{Literature Review}

We conducted a literature review for all papers referencing $M$. zeteki or $M$. cf. zeteki to identify potentially misnamed species. Using the research databases Web of Knowledge (Clarivate Analytics, Massachusetts, United States), antweb.org (California Academy of Sciences, California, United States), hol.osu.edu (C.A. Triplehorn Insect Collection, Ohio, United States), and personal literature collections, we reviewed papers that were found by the search criterion "Trachymyrmex zeteki", "Trachymyrmex cf. zeteki", "T. zeteki", "T. cf. zeteki", "zeteki", and "cf. zeteki". We then selected articles that included M. cf. zeteki or M. zeteki as their focal research organism and recorded those that reported the deposition of voucher specimens. We disregarded research articles that did not use physical specimens (e.g., data from molecular databases).

\section{Morphometrics}

Nearly all measurement means (Welch's), and ranges (Wilcoxon) are different between the two species (Table 2). The samples of the junior synonym M. balboai are within the ranges of $M$. zeteki samples (see Table S4) and are morphologically similar to the M. zeteki type specimen. $M$. mikromelanos sp. nov. is on average smaller than M. zeteki except in the case of the frontal lobe index (FLI). Due to non-significant differences, FLI was excluded from analyses of males and gynes. We observed some overlap in the range of measurements for workers and for males between M. mikromelanos sp. nov. and M. zeteki. In contrast, gynes are very distinct with few overlapping ranges (Table 2).

WORKERS: For our worker partition, all 15 characters were significantly different between species ( $\mathrm{p}<0.003$; Table 2). Our NMDS converged on a two-dimensional solution with an acceptable stress level (stress $=0.1288$ ) and the Sheppard plot showed good association around the regression line (non-metric fit $\mathrm{R}^{2}=0.983$; linear fit $\mathrm{R}^{2}=0.933$; see Fig. S1a). The resulting NMDS plot shows some overlap between the ellipses, although each species forms a distinct cluster with few outliers (Fig. 1a). The vectors for head width (HW), scape index (SI), and petiole length (PL) showed the most strength and direction in the measurements relative to the NMDS axes (Fig. 1a). Additionally, the type specimens for M. mikromelanos sp. nov. and $M$. zeteki plotted within their own ellipses (Fig. 1a). While the M. mikromelanos sp. nov. type and paratype specimens fall within the overlap of ellipses for both species, they remain morphologically distinct (see diagnosis and description). For M. mikromelanos sp. nov., SI and FLI explain separation from the M. zeteki cluster; while HW, eye length (EL), and frontal lobe FL explain separation from M. mikromelanos sp. nov. for M. zeteki. However, PL and waist length (WaL) best explain variation within clusters along the $\mathrm{Y}$ axis. Lastly, the two synonymized M. balboai syntype ('cotype') samples fall well within the M. zeteki ellipses. 
272 GYNES: For the gyne partition, all but FLI $(\mathrm{p}=0.6110)$ were significantly different between

273 species $(\mathrm{p}<0.003$; Table 2$)$. The NMDS converged on a two-dimensional solution with a robust 274 stress level (stress $=0.1119$ ), and the Shepard plot showed a strong association around the 275 regression line with a single outlier (non-metric fit $\mathrm{R}^{2}=0.986$; linear fit $\mathrm{R}^{2}=0.941$; see Fig. 276 S1b). The NMDS plot showed M. mikromelanos sp. nov. and M. zeteki each forming distinct 277 clusters with two outliers (Fig. 1b). The M. mikromelanos sp. nov. paratype gyne fell well within 278 the M. mikromelanos sp. nov. cluster (Fig. 1b). The vectors EL, SI, and PL showed the most 279 strength in directionality of the measurements relative to the NMDS axes (Fig. 1b).

280 MALES: For our male partition, all but FLI $(\mathrm{p}=0.0307)$ were significantly different between 281 species (Table 2). The NMDS converged on a two-dimensional solution with a robust stress level 282 (stress $=0.1554)$. The Shepard plot also showed relatively high correlation with the regression 283 line (non-metric fit $\mathrm{R}^{2}=0.976$; linear fit $\mathrm{R}^{2}=0.886$; see Fig. S1c). The NMDS plot showed $M$. 284 mikromelanos sp. nov. and $M$. zeteki each forming distinct clusters with no outliers. The vectors 285 for PL, mesosoma length (ML), SL, and cephalic index (CI) show the most strength in 286 directionality of the measurements relative to the NMDS axes (Fig. 1c). The paratypes for both 287 males fell well within their species clusters.

288 Our morphometric analysis shows that M. mikromelanos sp. nov. and M. zeteki are distinct 289 species while supporting the previous synonymy of M. balboai under M. zeteki by Weber 290 (1958b). Nearly all of the measurements taken are significantly different for all castes. The 291 NMDS plots reflect the overlap of some measurements observed in workers and males while 292 depicting clear separation of measurements observed in gynes.

\section{Behavioral Assay}

294 The tempo of worker activity differed between the two species (Fig. 1d). A gamma distribution 295 with an inverse link function was the best fit model (Table 3). For our diagnostic analysis of our 296 GLMM see supplementary material (Figs. S2-S4). The gamma inverse model shows that tempo 297 was correlated with species (Table 3, $\operatorname{Pr}(>|z|)=1.150 \times 10^{-02}$ ) and the variance of the random 298 effect (colony) was not significant (var. $=7.977 \times 10^{-02}$ ). This indicates that the variation observed 299 in tempo was associated with species identity rather than with the particular colony of origin. 300 This result provides further support for the delimitation between M. zeteki and M. mikromelanos 301 sp. nov.

\section{Phylogenetic analysis}

303 Using published data (Nygaard et al., 2016; Solomon et al., 2019) located in GenBank 304 (Mycetomoellerius zeteki genome: GCA_001594055.1) and the Mycetomoellerius gene 305 sequences (Dryad DOI: doi:10.5061/dryad.2p7r771; GenBank accession numbers Table S2) we 306 found genetic differences between M. mikromelanos sp. nov. and M. zeteki, with the former 307 supported as genetically distinct from the latter by $100 \%$ bootstrap support (Fig. 1e). We located 308 scaffolds for four genes (i.e., $E F 1 \alpha-F 1, E F 1 \alpha-F 2, L w R h$, and $W G$ ) and found high support for 309 each in the published genome. For the mitochondrial gene COI, commonly used for DNA 
310 barcoding (Simon et al., 1994), 12 scaffolds were identified in the M. zeteki genome and only 311 five had $>95 \%$ query cover (Table S3) suggesting the presence of pseudogenes and rendering 312 this marker unreliable (Anderson \& Leite, 2012). Based on the BIC scores, Modelfinder joined $313 E F 1 \alpha-F 1+W G$ (62 unique and 19 informative of 1777 sites) and $E F 1 \alpha-F 2+L w R h$ (13 unique 314 and 6 informative of 972 sites) partitions and found the K2P+I and K2P to be the best fit models 315 for those partitions respectively. The samples RMMA090930-09, RMMA050105-29, 316 JSC030826-01, and the genomic scaffold sequences used (GCA_001594055.1) were identified 317 as identical. Our phylogenetic analysis using four genes provided strong support for identifying 318 the Nygaard et al. (2016) genome as belonging to M. mikromelanos sp. nov. rather than to $M$. 319 zeteki as reported.

320

321

322

323

324

325

326

327

328

329

330

331

332

333

334

335

336

337

338

339

340

341

342

343

344

345

346

347

348

\section{Chemical analysis}

We found five farnesene compounds in M. mikromelanos sp. nov. and M. zeteki workers (1) E- $\beta$ farnesene, (2) (3Z,6E)- $\alpha$-farnesene, and (3) (3E, $6 \mathrm{E})-\alpha$-farnesene, in whole samples and gaster trisections. Farnesenes have been reported before and are presumably localized in the gaster, functioning as trail pheromones (Adams et al., 2012; Figs. 1f \& 1g; Table 4). (3E,6E)- $\alpha-$ farnesene (3) is most abundant in M. mikromelanos, averaging $69.3 \%$ of the observed farnesenes. (1) and (2), are each at less than $23 \%$ of the overall abundance in $M$. mikromelanos sp. nov. E- $\beta$ farnesene (1), is the most abundant (62.2\%) in M. zeteki with (2) at 18.4\% and (3-5) with 6.5\%.

These results illustrate that unique worker chemical profiles distinguish the two species. Some samples contained dilute concentrations of compounds as seen by the relative abundance (Fig. If \& 1g). One M. mikromelanos sp. nov. colony (CRC170518-08) has a chemical profile similar to M. zeteki, with (1) $56.9 \%$, (2) $33.7 \%$, and (3) $9.3 \%$. While this one colony stands out, all of the colonies of M. mikromelanos sp. nov. analyzed are morphologically distinct from M. zeteki and fit the description of M. mikromelanos (see Taxonomy section).

\section{Literature Review}

We found 63 articles that used M. zeteki or M. cf. zeteki under our search criteria (see Appendix Table S1). Twenty-eight articles did not identify the repositories of their voucher specimens, and of these, three articles deposited online sequence vouchers for ant specimens but mentioned no corresponding voucher specimens; nine others deposited symbiont vouchers (two fungal cultivar and seven non-cultivar symbionts). Voucher specimens were deposited in museums around the globe (Appendix Table 1), with the greatest number (fifteen) deposited at the Smithsonian Institution National Museum of Natural History, United States (USNM). The full list of voucher repositories includes: Colección Nacional de Referencia Museo de Invertebrados Universidad de Panamá (Panama); Smithsonian Tropical Research Institute Panama (Panama); Museu de Zoologia da Universidade de São Paulo (Brazil); Instituto Nacional de Biodiversidad (Costa Rica); Museo de Entomología de la Universidad del Valle (Colombia); Museo Entomológico Universidad Nacional Agronomía Bogotá (Colombia); Museum at the Universidad Técnica Particular de Loja (Ecuador); Natural History Museum of Denmark, (Denmark); Zoological Museum of the University of Copenhagen (Denmark); Zoological Museum, University of Puerto 
349 Rico (Puerto Rico); and the Smithsonian Institution National Museum of Natural History, 350 (United States of America).

351 Mycetomoellerius mikromelanos sp. nov. Cardenas, Schultz, \& Adams, new 352 species

353 Figures 2 and 3 include M. mikromelanos.

354 Geographic range: Panama: Colón, Darién, and Panama Province (RMMA and Jack Longino 355 (JTL) specimens).

356

357

358

359

360

361

362

363

364

365

366

367

368

369

370

371

372

373

374

375

376

377

378

379

380

381

382

383

384

Label text: Separate labels for each specimen indicated by brackets (e.g., [Label 1] [Label 2]).

HOLOTYPE: Worker, Republic of Panama. [9.16328, -79.74413, Panama: Colón Province, Pipeline Rd, 16E, 62m, 13.v.2017, Cody Raul Cardenas, CRC170513-04] [USNMENT01123723]. Repository: USNM.

PARATYPES: 15 Workers, Republic of Panama. Same label data as holotype. Repositories: USNM (3): USNMENT01123726, USNMENT01123727, USNMENT01123728; MZSP (4): OSUC 640618, OSUC 640619, OSUC 640620, OSUC 640621; STRI (5): OSUC 640635, OSUC 640636, OSUC 640637, OSUC 640638, OSUC 640639; OSUC (3): OSUC 640606, OSUC 640607, OSUC 640608.

PARATYPES: 11 Gynes, Republic of Panama. Same label data as holotype. Repositories: USNM (4): USNMENT01123724, USNMENT01123729, USNMENT01123730, USNMENT01123731; MZSP (3): OSUC 640622, OSUC 640623, OSUC 640624; STRI (3): OSUC 640640, OSUC 640641, OSUC 640642; OSUC (1): OSUC 640609.

PARATYPES: 7 Males, Republic of Panama. Same label data as holotype. Repositories: USNM (4): USNMENT01123725, USNMENT01123732, USNMENT01129733, USNMENT01129734; MZSP (1): OSUC 640625; STRI (1): OSUC 640643; OSUC (1): OSUC 640610.

HOLOTYPE/PARATYPE Colony Code: CRC170513-04.

Additional material examined:

Workers N=12: USNM: 3 specimens sharing label data [PANAMA: Pipeline RD, La Seda River; $79.736^{\circ} \mathrm{W} 9.1529^{\circ} \mathrm{N} ; 28$ v 2010;] [Henrick H. De Fine Licht; nest series; river bank; underground' HDFL28052010-4 ch1][Trachymyrmex zeteki] [Check cryo] [DO NOT REMOVE SI DB Reference Not a property tag T. Schultz, NMNH] USNMENT00752565, USNMENT00752578, USNMENT00752579; 4 specimens sharing label data [PANAMA: Pipeline Rd, La Seda River; $79.736^{\circ}$ W, 9.1529 'N; 28 v 2010;] [Henrik H. De Fine Licht nest series; river bank; underground HDFL28052010-5] [Trachymyrmex zeteki] [See cyro collections] [DO NOT REMOVE SI DB Reference Not a property tag T. Schultz, NMNH]: USNMENT00752574, USNMENT00752580, USNMENT00752581, USNMENT00752582; 3 specimens sharing label data [PANAMA: Pipeline Road, 2km past Limbo River 12v2010] [Henrik H. De Fine Licht; nest series; river bank; underground HDFL120502010-14] 
385

386

387

388

389

390

391

392

393

394

395

396

397

398

399

400

401

402

403

404

405

406

407

408

409

410

411

412

413

414

415

416

417

418

419

420

421

422

[Trachymyrmex zeteki] [See also cryo collections] [DO NOT REMOVE SI DB Reference Not a property tag T. Schultz, NMNH]: USNMENT00752565, USNMENT00752578 (1 pin with 2 specimens), USNMENT00752579. JTL: 1 specimen [PANAMA, Darién: 5 km S Platanilla $8.78105-78-.41251 \pm 20 \mathrm{~m} \mathrm{160m}, 20 \mathrm{an} 2015 \mathrm{~J}$. Longino\#9082] [2nd growth veg. stream edge nest in clay bank] [CASENT0633645].

Males N=3: USNM: 3 specimens sharing label data [PANAMA: Pipeline Road, $2 \mathrm{~km}$ past Limbo River 12v2010] [Henrik H. De Fine Licht; nest series; riverbank; underground HDFL120502010-14] [Trachymyrmex zeteki] [See also cryo collections] [DO NOT REMOVE SI DB Reference Not a property tag T. Schultz, NMNH] USNMENT00752576, USNMENT00752578 ( 1 pin with 2 specimens).

Note: A name previously applied to this species, Trachymyrmex fovater, was incorrectly electronically published in a conference poster format and is therefore unavailable (Cardenas et al., 2016). This name is unavailable because (i) the date of the publication was not indicated on the poster and (ii) the name was not registered in the Official Register of Zoological Nomenclature (ICZN 1999). We hereby describe Mycetomoellerius mikromelanos sp. nov. (LSID: urn:1sid:zoobank.org:act:B6BABA13-708F-44D8-AD2C-F4D5B8FB03E8), a name more appropriate for this species (see Etymology) and provide a complete diagnosis and description of this new species.

Diagnosis: Measurements for all castes are in Tables 2 and S4. We found characters that reliably separate M. mikromelanos sp. nov. from M. zeteki. However, due to the variability of worker castes (e.g., mesosoma spines), intermediate character states occur in some individuals. The following characters are those most useful for diagnosis.

Workers 1) cuticle coloration dark-ferrugineous (Figs. 2a-2c); 2) overall integument bearing granulose irrorate sculpturing (Figs. 2a-2c); 3) frontal lobe with crenate margins and weak antero-lateral spine (Fig. 2b); 4) hooked spatulate bi-colored setae medial to frontal carina on disc of head capsule (Fig. 2b); 5) scape surpassing occipital corners when lodged in antennal scrobe (Fig. 2b); 6) convex margin of the compound eye extending past the lateral border of the head by more than half of its visible diameter in full-face view (Fig. 2b).

Gynes 1) cuticle coloration dark-ferrugineous (Figs. 2d-2f); 2) supraocular spine superior to compound eye by more than or equal to the eye length (Fig. 2d);3) small arcuate ridge superior to and reaching anterior ocellus, with its terminal ends directed postero-laterally (Fig. 2d); 4) lateral ocelli partially obscured in full-face view (Fig. 2d); 5) mesoscutum with randomreticulate sculpturing (Fig. 2f \& S5a); 6) wings bicolored, venation ferrugineous-brown (Figs. 2e, 2f, \& S5b); 7) hindwing with 7-9 hamuli (Figs. 2e \& S5b).

Males 1) bicolored; head and mesosoma ferrugineous-brown; metasoma dark testaceous-orange (Fig. 3a); 2) complete carinate-rugulose sculpturing of posterior head capsule, arranged nearly perpendicular to the longitudinal axis of the head (Fig. 3a); inferior to frontal lobe, sculpturing sparsely carinate and finely reticulate (Figs. 3a \& S6); 3) mandible distinctly smaller compared 
423 to $M$. zeteki; 4) corners of medial clypeal emargination rounded (Figs. 3b \& S6) ocelli smaller 424 relative to $M$. zeteki in full-face view, occipital corner of head capsule visible (Fig. 3b); 6) 425 propodeal spines wider at base than long (Fig. 3a).

426 WORKER: Overall pilosity is strongly bicolored, terminating with light coloration when 427 spatulate; unless otherwise noted curved, appressed, and simple (Figs. 2a-2c). Older workers 428 dark-ferrugineous; younger workers ferrugineous-orange. Integument typically with granulose irrorate sculpturing and a variably present white cuticular bacterial bloom.

Head: Disc of head capsule bears spatulate bi-colored setae (Fig. 2b); weakly granulose

432

433

434

435

436

437

438

439

440

441

442

443

444

445

446

447

448

449

450

451

452

453

454

455

456

457

458

459

460

461 sculpturing; in full-face view broader than long. Mandible feebly sinuous, with 6-9 denticles. Palpal formula 4,2. Median margin of clypeus impressed; lateral-most corners of impression distinctly angulate. Preocular carina originate from mandibular insertion and terminate at occipital corners by a stout multituberculate tumulus directed postero-laterally. Frons with simple bi-colored setae. Frontal lobe semicircular; crenate margins and weak antero-lateral spine (Fig. 2b); frontal carina extending from posterior margins reaching occipital corners, joining the sub-parallel preocular carina to form antennal scrobes. Eye with 6-7 facets across width; eye margin extending past the lateral border of the head by more than half of its visible diameter in full-face view (Fig. 2b). Antenna with 11 segments; when lodged in antennal scrobe scape surpasses occipital corner (Fig. 2b); scape wide proximally and weakly tapering before thickening sub-distally; scape narrow at apex. Supraocular projection stout and multituberculate. Vertex impression shallow and narrow, but variable.

Mesosoma: Erect and strongly curved spatulate setae typically occurring from, or near, tubercles or spines; sparse rugulose sculpturing; most mesosomal sclerites with fine granulate sculpturing. Pronotum with fused median pronotal tubercles; superior lateral pronotal spine project anterolaterally; inferior lateral pronotal spines that project anteroventrally; in most cases the median pronotal spine projects as far or farther than lateral pronotal spine. Coxa I with entirely simple weakly bicolored setae; subtle superior impression on its anterior margin. Coxae II and III have spatulate setae on parallel carina dorso-laterally. Legs with spatulate setae proximally gradually becoming simple, appressed, and pale distally. Propodeum, in lateral view presents tuberculate carina at anterior base of propodeal spine; superior margin of metapleural gland bulla with variable number of tubercles; carina occurring from spiracle to propodeal lobes.

Metasoma: Petiolar nodes granulate and present a variable number of spines. Petiole with spatulate seta medially and posteriorly; intermittent carina comprised of tubercles; carina turn weakly mesad anteriorly but do not touch each other; lateral posterior margin weakly convex; in dorsal view anterior margins rounded (Fig. 2c); in dorsal view lateral margins subtly crenulate and weakly concave sub-anteriorally; ventral carinae converges to sub-petiolar process. Postpetiole with spatulate setae scattered dorsally and laterally; pair of simple setae ventrally; dorsal carina comprised of tubercles; in dorsal view, broader than long dorsally; posterior margin flat medially, with medial impressions on lateral margins. Gaster tergites and sternites with spatulate setae anteriorly; posterior margin of first tergite with subtly curved, simple setae; all 
462 other tergites and sternites with simple setae that become gradually finer and lighter posteriorly;

463

464

465

466

467

468

469

470

471

472

473

474

475

476

477

478

479

480

481

482

483

484

485

486

487

488

489

490

491

492

493

494

495

496

497

498

499

weak reticulate sculpturing; triangular; in lateral view mostly round; first gastral tergite has crenate postero-lateral corners that surpass thin shiny margin between tergites I and II.

GYNE: Dark, curved, and simple setae unless otherwise noted; queens uniform ferrugineousorange color; increasingly dark-ferrugineous with age. Integument generally with irrorate sculpturing and a variably present white cuticular bacterial bloom (Figs. 2d-2f).

Head: Setae of head capsule dark, curved, appressed, and simple; disc of head capsule bearing some spatulate setae; prominent sculpturing throughout; in full-face view, head longer than broad. Mandible feebly sinuous, with 6-8 denticles. Clypeus with minute tubercles scattered from anterior margin to slightly anterior of frontal lobes. Frontal lobe disc weakly rugulose; antero-lateral margin with reduced spine; semicircular; carina interior and parallel to margins. In full-face view, at least three quarters of the anterior lateral margin of compound eye surpassing lateral margin of head capsule; supraocular spine separated from compound eye by as much or more than the eye length (Fig. 2 d; i.e., $E L=0.27 \mathrm{~mm}$, distance to supraocular spine $=0.31 \mathrm{~mm}$ ). Antennal scape wide proximally and tapering slightly before thickening sub-distally. Vertex carina extending from ocelli to frontal carinae; small arcuate ridge touches posterior margin of ocellus superior to anterior ocellus with terminal ends directed variably laterally and posteriorly but never anteriorly. Vertex variably impressed, but generally shallow and narrow.

Mesosoma: Sclerites with spatulate setae; confused-rugulose sculpturing. Pronotum with stout medial spine projecting anteriorly; superior lateral pronotal spine projecting antero-laterally; inferior lateral pronotal spine flattened laterally and projecting ventro-laterally. Coxa I with dark curved anterior setae and minute dense lightly colored pilosity throughout; weak asperous sculpturing on lateral face. Coxa II with bicolored weakly to fully spatulate setae along parallel carinae; a row of thick, dark, curved setae on posterior side in lateral view; rugulose sculpturing lateral to carinae. Coxa III has bicolored weakly to fully spatulate setae along carinae otherwise simple setae throughout; rugulose sculpturing lateral to carinae. Mesoscutum with appressed weakly spatulate to simple bicolored setae; random reticulate sculpturing. Mesoscutellar disc with appressed setae; random reticulate sculpturing (Figs. 2f \& S5a); two small posteriorly projecting spines. Axilla hides scutoscutellar sulcus. Katepisternum and anepisternum suture embossed with strigate sculpturing. Inferior margin of anepisternum crenulate. Propodeal declivity nearly vertical.

Wings: with a fine pubescence. Tegula with fine curved setae; triangular; weakly impressed on its face. Axillary sclerite with fine curved setae; flattened along distal margin. Forewing tinted smokey gray, more so anteriorly and less so posteriorly; venation ferrugineous-brown; with five cells (Figs. 2f \& S5b); length of radial sector-media greater than half the length of the radius radial sector (Fig. S5b). Hindwing with long fine setae on posterior margin, longer proximally than distally; tinted smokey gray, more so anteriorly and less so posteriorly; venation ferrugineous-brown; two cells; 7-9 hamuli (Figs. 2d, 2f, \& S5b).

Peer) reviewing PDF | (2020:12:56021:1:1:NEW 8 May 2021) 
500 Metasoma: Petiole with weakly curved and bicolored setae, variably spatulate to simple; dorsal 501 carinae of petiole with parallel spines that touch posterior margins; dorsal carinae

502 directed medioanteriorly but not joining; ventral carinulae converging posteriorly on sub-

503 petiolar process. Post-petiolar dorsum with distinct tubercles; lightly impressed medially; in

504 dorsal view bearing two impressions on postero-lateral margins. Gaster with mostly simple setae, 505 very few spatulate setae; terminal tergites have dense, lightly colored setae surrounded by dark

506 setae; setae becoming less appressed towards terminal tergites and sternites; generally with

507 strong confused reticulate sculpturing. First sternite and first tergite with confused-

508 reticulate sculpturing; tergites I-IV have crenulate carinae bordering narrow shiny posterior 509 margin.

510 MALE: Strongly appressed dark pilosity; mature males bicolored; head and mesosoma

511 testaceous-orange and dark-ferrugineous, in part due to darkened sculpturing; metasoma

512 testaceous-orange (Fig. 3a); integument with weak to effaced rugulose sculpturing (Fig. 3a).

513 Head: Pilosity dark and appressed to weakly appressed and curved; head capsule generally with 514 carinate-rugose sculpturing; but sparsely carinate and finely reticulate inferior and lateral to 515 frontal lobe; striate sculpture of head capsule in profile arranged nearly perpendicular to the 516 longitudinal axis of the head (Fig. 3a; see also Fig. S6); head capsule in full-face view wider than 517 long (Fig. 3b). Mandible with sparse, pale, and appressed setae; apical masticatory margin darker 518 than rest of mandible; elongate-triangular and feebly sinuous; external margin feebly sinuate;

519 prominent apical teeth; 4-6 mostly uniformly teeth. Clypeus absent to weakly sculptured; 520 evenly rounded; narrow shiny anterior margin. Frons bulbous with weak to effaced carinate

521

522

523

524

525

526

527

528

529

530

531

532

533

534

535

536

537 sculpturing across its entirety, forming two small mounds inferior to the frontal lobes. In lateral view, preocular carina occur near mandibular insertion, continue along inner margin of eye variably extending posterad. Frontal lobe with fine pilosity along margin but strongly curved setae on disc; strongly impressed medially; otherwise, smooth margin (Fig. 3b). Antennae covered with very fine lightly colored setae appressed (Fig. 3b); 13 segments; neck of scape and basal condyle visible (Fig. 3b); scape wide proximally, gently narrowing to apex. In full-face view lateral ocelli prominent and parallel to a shallow vertex impression (Fig. 3b). Supraocular projection absent or weak when, occurring directed posteriorly and near ocellus in full-face view.

Mesosoma: Setae strongly appressed throughout; sculpturing weak to effaced carinulaterugulous, finely reticulate where carinulate-rugulous sculpturing absent. Pronotum with minute lateral spines projecting antero-laterally; median pronotal tubercle varying from clearly visible to greatly reduced, best seen laterally; forward-projecting median pronotal tubercle near mesoscutum and pronotal suture; inferior corner of pronotum, anterior to coxa I, carinae bear extremely reduced or absent inferior spine. Coxa mostly covered with light-colored setae. Coxa I with carinulate-rugulose sculpturing; coxa II with dark prominent setae posteriorly near trochanter; coxa I longer than coxa III, coxa II shortest. Mesoscutum, in lateral view, rounded and bulbous anteriorly, bulging over pronotal-mesoscutal suture. Mesoscutellar disc with two 
538 very small, posteriorly projecting spines. Propodeum with small posterior spines that are wider,

539

540

541

542

543

544

545

546

547

548

549

550

551

552

553

554

555

556

557

558

559

560

561

562

563

564

565

566

567

568

569

570

571

572

573

574

575

or as wide at the base as long, projecting postero-laterally (Fig 3a).

Wings: Overall pubescence fine. Forewing weakly bicolored; five cells; media-cubitus vein exceeds half-length of anal vein after the cubitus-anal vein proximally; length of radial sectormedia greater than half the length of the radius radial sector. Hindwing with long fine setae on posterior margin, longer proximally than distally; uniform coloration, 6-8 hamuli.

Metasoma: Overall pilosity appressed; weakly sculptured; somewhat bicolored. Petiole with few curved and appressed setae dorsally; weakly costulate sculpturing; rounded; spiracle anterior to center; dorsally the lateral margins impressed, with anterior spine larger. Postpetiole with few curved and appressed setae dorsally; two ventral setae; in lateral view nearly rectangular; posterior margin shallowly impressed. Setae of first gastral tergite and sternite appressed; those on tergites 2-5, weakly appressed along posterior margins fine reticulate sculpturing. Pygostyle and genital opening densely covered with lightly colored setae.

\section{Etymology}

"Mikromelanos" is a singular, masculine adjective, compounded from the Greek $\boldsymbol{\mu \iota \kappa \boldsymbol { ⿰ }} \boldsymbol{\varsigma}$

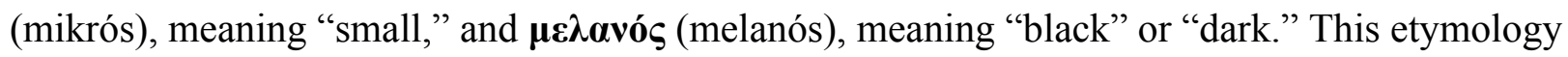
highlights the authors" colloquial use of "little black" to describe the small darker queens of $M$. mikromelanos.

\section{Comments}

Although M. mikromelanos shares many similarities with M. zeteki (Figs. 2-5; Weber 1940, 1958b; Mayhé-Nunes \& Brandão 2007), certain key characters allow us to easily distinguish the two species with a $20 \mathrm{X}$ loupe in the field. These key characters in M. mikromelanos are (i) the worker scapes extend past the occipital corners of the head capsule (extending only to the occipital corners in $M$. zeteki), (ii) gyne wing venation is ferrugineous-brown in $M$.

mikromelanos and testaceous-orange in M. zeteki, (iii) queens of M. mikromelanos are typically smaller and a dark reddish brown, where $M$. zeteki queens are larger and a bright reddish color, (iv) males are bi-colored, dark-ferruginous and testaceous-orange (uniform, testaceous-orange in M. zeteki), and (v) in general, all castes of M. mikromelanos are smaller than those of M. zeteki. Distinguishing between the gynes or queens of M. mikromelanos and M. zeteki, however, requires a microscope. Aside from size, it is most informative to look at sculpturing of the mesoscutum under a microscope: $M$. mikromelanos gynes have random reticulate sculpturing on the mesoscutum whereas $M$. zeteki have parallel sculpturing. In addition to color differences, males of the two species can be differentiated by the integumental sculpture near the eye. In the male of M. mikromelanos ocelli are small and in lateral view the striations follow the contours of the ventroposterior borders of the eye (Figs. 3a \& S6). Whereas M. zeteki ocelli are large and striations fan outward from the ventroposterior corner of the head and are interrupted by the borders of the eye and the preocular carina, where they end (Figs. 5a \& S10). A complete list of measurements is provided in the supplementary material. 


\section{Biology}

577 Mycetomoellerius mikromelanos is the most common 'funnel Mycetomoellerius' found on

578 Pipeline Road, near Gamboa, Panama. Gynes establish nests from the start of the rainy season

579 (May) into July. They nest in vertical clay embankments with entrances shaped like funnels (i.e.,

580 auricles) with flared margins (Mueller \& Wcislo, 1998; Pérez-Ortega et al., 2010). Colonies are

581 often tucked under roots or overhangs and occur in high densities (as close as $\sim 5 \mathrm{~cm}$ apart) along

582 creeks or are isolated in the forest at the base of trees. Colonies of M. mikromelanos have up to

583 five vertically arranged chambers with single vertical tunnels between them. We removed the

584 auricles from 16 nests and 15 were rebuilt to roughly the same size within seven days, suggesting

585 the funnel structure appear to be biologically important (Fisg. S7 \& S8; also see Mueller \&

586 Wcislo, 1998; Schultz et al., 2002; Pérez-Ortega et al., 2010; Helms et al., 2014). Several

587 functional hypotheses have been proposed from physical barriers for army-ant raids to visual

588 nest recognition cues. But nest entrances could also be involved in gas exchange currents that

589 disperse colony odors or assist with colony respiration (see Longino, 2005; Helms et al., 2014).

590 Further research is necessary to clarify their biological function.

591 A variety of organisms exploit the resources of $M$. mikromelanos (e.g., fungal garden, shelter, 592 brood). Megalomyrmex adamsae Longino 2010, a rare obligate social parasite (1-6\% parasitism

593 rate), forages on the host garden and brood and never leaves the nest of M. mikromelanos

594 (Adams et al., 2012b). Escovopsis Muchovej \& Della Lucia 1990, an assumed micro-filamentous

595 fungal parasite, is maintained at low levels due to specialized grooming behaviors used by

596 workers of M. mikromelanos (Currie, Mueller \& Malloch, 1999; Currie et al., 2003; Little et al.,

597 2003, 2006). Other fungi such as Trichoderma (Persoon, 1794) threaten the health of the garden

598 and are managed by the ants (Currie et al., 2003; Little et al., 2006). There are also six Diapriinae

599 (Hymenoptera: Diapriidae) morphospecies exploiting M. mikromelanos, but little natural history

600 has been reported for these associations (but see Pérez-Ortega et al., 2010). Diapriinae parasitoid

601 wasps infiltrate nests and parasitize host larvae, turning them black as the wasps develop

602 internally. We found that mature wasp pupae can be prompted to eclose when disturbed or

603 picked up and male Acanthopria sp. Ashmead 1895 tend to naturally emerge before Acanthopria

604 females in captive colonies (ca. 10 days; deposited in the RMMA collection). We also found that

605 Mimopriella sp. Masner \& García 2002 can take up to six months to complete development in a

606 laboratory-maintained colony. The mechanism behind this unusually slow growth is unknown.

607 These symbionts highlight the known diversity of a species network that is reliant on $M$.

608 mikromelanos for survival.

609 Mycetomoellerius zeteki (Weber, 1940)

610 Figures 4 and 5 include $M$. zeteki.

611 Geographic range: Colombia, Costa Rica, Ecuador, Panama (Mayhé-Nunes \& Brandão, 2007)

612 Label text: Separate labels for each specimen indicated by brackets (e.g., [Label 1] [Label 2]). 
613 LECTOTYPE (here designated): Worker; [Barro Colorado. CANAL ZONE No. 856 NAWeber 614 1938] [Trachymyrmex zeteki Weber COTYPE] [USNMENT01129855]. Repository: Museum of 615 Comparative Zoology, United States of America (MCZ).

616 PARALECTOTYPE (here designated, examined): Worker; [Barro Colo. I. Canal Zone No.756 617 NAWeber 1938] [M.C.Z. CoType 25619] [T. zeteki Weber Cotypes] [Harbor Islands Insect 618 Database] [MCZ-ENT 00025619]. Repository: MCZ.

619 Additional material examined

620 Workers N =24: MCZ: 1 specimen with the label data [Barro Colo. I. Canal Zone No756 621 NAWeber 1938 walking at 9 pm. Snyder-Molino 0-4.] [762 1 worker USNM]; 1 pin with 2 622 specimens [Barro Colo. I. Canal Zone No. 759 NAWeber 1938] [T. balboai Weber Cotypes]. 623 NHMB: 1 specimen with the label data [Barro Colo. I C.Z. 3441 NAWeber] [Trachymyrmex 624 zeteki Weber] [17.vi.56 3441] [ANTWEB CASENT 0912534]; NOTE: The NHMB pin bears a 625 "type" label, but we assume it to be erroneous because the specimen was collected in 1956 and 626 therefore cannot be part of Weber's 1938 M. zeteki syntype series. USNM: 3 specimens sharing 627 these label data [PANAMA: Pipeline Rd; 19 v 2010; Henrik H. De Fine Licht; nest series; river 628 bank; underground; HDFL1952010-8] [see also cyro collections] [Trachymyrmex sp's] [DO 629 NOT REMOVE SI DB Reference Not a property tag T. Schultz, NMNH] USNMENT00752570 630 (1 pin with 2 specimens), USNMENT00752572. 16 specimens sharing these label data: [9.1624,631 79.74802, PANAMA: Colón, Pipeline Rd, Bird Plot 4E19N, 70m, 29.vi.2010, Rachelle MM 632 Adams, RMMA100629-15] [Formicidae Myrmicinae Trachymyrmex zeteki, Weber 1940, det. 633 Cardenas, CR., 2018]. Repositories: USNM (4): USNMENT01129711, USNMENT01123714, 634 USNMENT01123715, USNMENT01123716; MZSP (4): OSUC 640611, OSUC 640612, OSUC 635 640613, OSUC 640614; STRI (5): OSUC 640626, OSUC 640627, OSUC 640628, OSUC 636 640629, OSUC 640630; OSUC (3): OSUC 640601, OSUC 640602, OSUC 640603.

637 Gynes N = 9: Sharing these label data: [9.1624, -79.74802, PANAMA: Colón, Pipeline Rd, Bird 638 Plot 4E19N, 70m, 29.vi.2010, Rachelle MM Adams, RMMA100629-15] [Formicidae

639 Myrmicinae Trachymyrmex zeteki, Weber 1940, det. Cardenas, CR., 2018]. Repositories: USNM 640 (4): USNMENT01123712, USNMENT01123717, USNMENT01123718, USNMENT01123719. 641 MZSP (2): OSUC 640615, OSUC 640616; STRI (2): OSUC 640633, OSUC 640634; OSUC (1) 642 OSUC 640604.

643 Males N = 11: USNM: 3 specimens sharing these label data [PANAMA: Pipeline Rd; $19 \mathrm{v} 2010$; 644 Henrik H. De Fine Licht; nest series; riverbank; underground; HDFL1952010-8] [see also cyro 645 collections] [Trachymyrmex sp's] [DO NOT REMOVE SI DB Reference Not a property tag T. 646 Schultz, NMNH] USNMENT00752568 and USNMENT00752570 (1 pin with 2 specimens). 647 Sharing these label data: [9.1624, -79.74802, PANAMA: Colón, Pipeline Rd, Bird Plot 4E19N, 648 70m, 29.vi.2010, Rachelle MM Adams, RMMA100629-15] [Formicidae Myrmicinae 649 Trachymyrmex zeteki, Weber 1940, det. Cardenas, CR., 2018]. Repositories: USNM (4):

650 USNMENT01123713; USNMENT01123720; USNMENT01123721; USNMENT01123722;

651 MZSP (1): OSUC 640617; STRI (2): OSUC 640633, OSUC 640634; OSUC (1): OSUC 640605. 
652 Mycetomoellerius zeteki was originally described by Weber (1940) as Trachymyrmex zeteki from 653 an accidental collection in dense shade on a slope near the lab on Barro Colorado Island, Panama 654 Canal Zone (Weber, 1940; Mayhé-Nunes \& Brandão, 2007). In the same article Weber followed 655 his description of T. zeteki with a description of T. balboai (Weber, 1940). These descriptions 656 were based on small series of workers from single collections. Weber noted similarities between 657 the two species in his original descriptions. According to Weber, T. zeteki was distinctly smaller 658 than T. balboai, paler in appearance, and the relative proportions of the thoracic spines differed. 659 The character states that Weber used to differentiate the two species were later understood to 660 represent variation within a single species and $T$. balboai was synonymized with $M$. zeteki

661 (Weber, 1958b). In Mayhé-Nunes and Brandão's (2007) revision of the Trachymyrmex 662

663 "Jamaicensis group," M. zeteki was placed in a subset of the "Iheringi group." Distinct

664

665

666

667

668

669

670

671

672

673

674

675

676

677

678

679

680

681

682

683

684

685

686

687

688

689

690 characteristics of the Jamaicensis group are the open antennal scrobes arising from the subparallel preocular and frontal carinae (Mayhé-Nunes \& Brandão, 2007), a character cited by Solomon et al. (2019) as applying to the entire genus Mycetomoellerius. Here we describe the gyne wing venation and males of $M$. zeteki and provide comparative morphology in the comments to delineate $M$. zeteki from M. mikromelanos. For complete descriptions of worker and gynes of M. zeteki, see Weber (1940, 1958b) and Mayhé-Nunes and Brandão (2007).

Diagnosis: Measurements for all castes are found in Table 2, S4. Certain characters are useful for separating M. zeteki from M. mikromelanos sp. nov. However, due to the variability of the worker castes (e.g., mesosoma spines), intermediate character states occur in some individuals. The following characters are most useful.

Workers 1) cuticle ferrugineous (Figs. 4a-4c; dark-ferrugineous in M. mikromelanos); 2) integumental sculpture weakly irrorate (Figs. $4 \mathrm{a} \& 4 \mathrm{~b}$; granulose irrorate sculpturing in $M$. mikromelanos); 3) frontal lobe with weakly crenulate margins and distinct antero-lateral spine (Fig. 4b; crenulations present and spines lacking in M. mikromelanos); 4) disc of head capsule between frontal carinae mostly lacking strongly hooked spatulate bi-colored setae (Fig. 4b; present in M. mikromelanos); 5) scape of antenna reaching occipital corners when lodged in antennal scrobe (Fig. 4b; surpassing occipital corners in M. mikromelanos); 6) convex margin of the compound eye extending past lateral border of head capsule by less than half of the eye area in full-face view (Fig. 4b; extending by more than half in M. mikromelanos).

Gyne 1) cuticle coloration ferrugineous (Figs. 4d-4f; dark-ferrugineous in M. mikromelanos); 2) supraocular tubercle separated from compound eye by a distance less than or equal to the eye length (Fig. 4d; more than or equal to eye length in M. mikromelanos); 3) small arcuate ridge superior to anterior ocellus with terminal ends directed antero-laterally (Fig. 4d; directed posterolaterally in M. mikromelanos); 4) lateral ocelli conspicuous in full-face view (Fig. 4d; partially obscured in M. mikromelanos); 5) mesosoma with sparse carinate sculpturing; mesoscutum with parallel-costulate sculpturing (Fig. 4f; random-reticulate in M. mikromelanos); 6) wing venation testaceous-orange brown (Figs. 4e \& 4f; wings weakly ferrugineous-brown in $M$. mikromelanos); 7) hindwing with 5-8 hamuli (Fig. 4e; 7-9 in M. mikromelanos). 
691 Male 1) coloration mostly uniform testaceous-orange (Fig. 5a; bicolored, head and mesosoma

692 ferrugineous-brown with metasoma dark testaceous-orange in M. mikromelanos); 2) striations on

693 head capsule fanning outward from ventroposterior corner of head, ending at the compound eye

694 and preocular carina (Figs. 5a \& S10; striations perpendicular to longitudinal axis in $M$.

695 mikromelanos); sculpture prominent on posterior head capsule, minute to absent anteriorly (Fig.

696 5a; nearly complete sculpturing of head capsule in M. mikromelanos); 3) mandible larger

697 compared to those of M. mikromelanos; 4) corners of clypeal emargination slightly angled (Fig.

6985 b; rounded in M. mikromelanos); 5) in full-face view; occipital corners of head capsule partially

699 obscured by large ocelli (Fig. 5b; visible in M. mikromelanos); 6) propodeal spines longer than

700 width of spine at base (Fig. 5a; wider at base than long in M. mikromelanos).

\section{GYNE:}

702 Wings: Overall pubescence fine. Tegula with dark appressed simple setae; testaceous-orange

703

704

705

706

707

708

709

710

711

712

713

714

715

716

717

718

719

720

721

722

723

724

725

726

727

728

729

coloration; triangular; impressed face. Axillary sclerite with setae along ventral margins and dark appressed setae on its face; flattened along distal margin. Forewing weakly tinted smokey grey, only slightly more so anteriorly than posteriorly; venation testaceous-orange/brown (Fig. 4f); five cells; length of radial sector-media vein less than half the length of radius-radial sector vein. Hindwing with long fine setae on posterior margin, longer proximally than distally; lightly tinted smokey grey, venation testaceous-orange/brown; 5-8 hamuli (Fig. 4d \& 4f).

MALE: Dark and weakly appressed setae; mature males nearly uniform testaceous-orange color; darkened sculpturing on head capsule, otherwise integument generally weak to effaced carinnulate-rugalose sculpturing (Fig. 5a).

Head: Poorly appressed curved dark setae; feebly darker than rest of body due to sculpturing; sculpturing carinulate-rugulose lateral and posterior to frontal lobes; sculpturing reduced posterior to median ocelli and in median portion of vertex; otherwise finely reticulate; striation on head capsule fanning outward from ventroposterior corner of head, ending at the compound eye and preocular carina (Fig. 5a \& 5b; see also S10); head capsule in full-face view wider than long (Fig. 5b). Mandible with fine and lightly colored setae; setae on external margin appressed; masticatory margin distinctly darker than rest of mandible; triangular and feebly sinuous; apical tooth prominent; with 5-7 dentate to denticulate teeth. Clypeal margin somewhat shiny; not evenly rounded; weak angle near clypeal emargination. Frons with carinulate-ruglose sculpturing forming two small mounds bearing curved setae inferior to frontal lobes; otherwise mostly smooth; somewhat bulbous. Preocular carina originating near mandibular insertion, continuing along inner margin of eye and extending variably posterad. Frontal lobe with fine pilosity along margin but dark simple setae on disc; lightly impressed medially; otherwise, smooth margin. Antenna with 13 segments; scape covered in fine and intermittent dark appressed setae; scape and basal condyle visible; scape wide proximally and gently tapering before widening subdistally to apex (Fig 5b). In full-face view ocelli large and distinct; central and lateral ocelli are prominent, large, and distinct; lateral ocelli parallel to the shallow vertex impression.

Supraocular projection directed posteriorly, visible in full-face view.

Peer] reviewing PDF | (2020:12:56021:1:1:NEW 8 May 2021) 
730 Mesosoma: Somewhat appressed setae throughout; carinulate-rugulous sculpturing; weakly

731

732

733

734

735

736

737

738

739

740

741

742

743

744

745

746

747

748

749

750

751

752

753

754

755

756

757

758

759

760

761

762

763

764

765

766

767

768

reticulate when carinulate-rugulous sculpturing absent. Pronotum with small lateral spine projecting anteriorly; minute to entirely absent spine occurs medially along anepisternum pronotal suture; inferior corner, near coxa I, with extremely reduced spine. Coxa covered mostly with lightly colored setae; weak carinulate sculpture. Coxa I with a few dark setae anteriorly. Coxa II with dark prominent setae mostly ventrally near trochanter. Length of coxa III equal to or longer than coxa I. Mesoscutum, in lateral view, rounded and bulbous anteriorly, bulging over pronotal-mesoscutal suture. Axilla hide part of scutoscutellar suture in lateral view.

Mesoscutellar disc with two very small, posteriorly projecting spines (Fig. 5a). Propodeal spines as long or longer than width of base and projecting posteriorly (Fig, 5a).

Wings: Overall pubescence fine. Forewing weakly bicolored; possessing five cell; media-cubitus vein less than half length of anal vein after cubitus-anal proximally; length of radius-radial sector vein less than half the length of radial sector-media. Hindwing with long fine setae on posterior margin, more so proximally than distally; uniform in coloration; 4-7 hamuli.

Metasoma: Mostly weakly appressed simple and subtly curved setae; uniform coloration; poorly sculptured. Petiole with curved setae dorsally; costulate sculpturing if present; node rounded; in profile spiracle present medially at anterior margin; in dorsal view antero-lateral tumuli flanking a flattened medial projection. Postpetiole sculpturing finely reticulate if present; posterior ventral side with spine present varying in length from absent to almost as long as postpetiole; in lateral view nearly square; shallow posterior impression. Gaster setae sparse and appressed; sculpturing finely reticulate; sternites and tergite setae sparse and appressed; sternite and tergite 2-5 with dark setae along posterior margins. Pygostyle and genital opening covered with lightly colored setae.

\section{Comments}

A specimen of M. zeteki deposited at the Natural History Museum, Basel Switzerland bears a "cotype" (i.e. syntype) label in error. The data label reads as follows '[Barro Colo. I C.Z. 3441 NAWeber] [17.vi.56 3441] [Trachymyrmex zeteki Weber] [ANTWEBCASENT0912534] [type].' It is not possible that this specimen, collected in 1956, 18 years after the M. zeteki type series was collected, is a type specimen of that species. While this specimen could be part of the material examined in Weber 1958b balboai-zeteki synonymy, no repositories were mentioned. This specimen was not treated as a syntype for this study. For a complete description of the workers and gyne of M. zeteki, see Mayhé-Nunes and Brandão (2007). Certain key characters allow us to easily distinguish $M$. zeteki from M. mikromelanos with a 20X loupe in the field. For $M$. zeteki these characters are (i) in workers of $M$. zeteki, the scapes reach the occipital corners of the head capsule but do not extend past them, whereas in M. mikromelanos, they extend past the head capsule when lodged in the antennal scrobe, (ii) the queens of $M$. zeteki are comparatively larger than those of $M$. mikromelanos and are typically bright reddish in color whereas $M$. mikromelanos are generally a darker reddish brown, (iii) gyne wing venation is testaceousorange in $M$. zeteki and ferrugineous-brown in M. mikromelanos, (iv) males are uniform in color

Peer) reviewing PDF | (2020:12:56021:1:1:NEW 8 May 2021) 
769

770

771

772

773

774

775

776

777

778

779

780

781

782

783

784

785

786

787

788

789

790

791

792

793

794

795

796

797

798

799

800

801

\section{Discussion}

803 Based on multiple lines of evidence, we have shown that the new species M. mikromelanos is a

804

805

806

and testaceous-orange (bicolored dark-ferrugineous and testaceous-orange in M. mikromelanos), and (v) in general all castes of M. zeteki are larger than M. mikromelanos. It is necessary to note that workers from incipient colonies of $M$. zeteki tend to resemble workers of M. mikromelanos and require careful attention to the additional variable characters. A complete list of measurements can be found in the supplementary material.

\section{$\underline{B i o l o g} y$}

Most reports of M. zeteki are most likely accounts of $M$. mikromelanos (Appendix Table 1). Mycetomoellerius zeteki is rare relative to M. mikromelanos in the Canal Zone near Gamboa, Panama. For example, we only located two colonies of M. zeteki near the type locality on Barro Colorado Island, and one colony at El Llano ca. $40 \mathrm{~km}$ east of the canal. On the mainland we have found mixed sites of both species and a single creek with only M. zeteki present (Rio Mendoza, ca. $1 \mathrm{~km}$ North of Rio La Seda), but when the two species occur together, M. zeteki always occurs at comparably lower densities. While some M. zeteki samples are indicated to be collected from Nicaragua we examined seven specimens from JTL and three specimens were morphologically distinct from the Panamanian M. zeteki and M. mikromelanos. Mycetomoellerius zeteki and M. mikromelanos are similar morphologically and biologically and this has led to confusion between these sister species. In both species, gynes establish their nests from the start of the rainy season (around May) into July. Nests can be found on the same clay embankments with indistinguishable auricles with up to five chambers. In the five mature $M$. zeteki nests we excavated, each had two tunnels connecting each chamber. In contrast $M$. mikromelanos has only one tunnel connecting them and there are likely other architectural differences, such as volume and internal auricle shape, but more colonies of M. zeteki need to be examined.

Mycetomoellerius zeteki and M. mikromelanos also have a similar range of symbionts.

Megalomyrmex adamsae associates with M. zeteki, foraging on host garden and brood, and never leaves the host nest (Adams et al., 2012b). An Escovopsis fungal parasite attacks the fungal garden. Garden maintenance behavior also appears similar as M. zeteki forms infrabuccal pellet piles like M. mikromelanos (Little et al., 2003). We have documented the first Diapriidae wasp parasitizing the brood of $M$. zeteki. In a laboratory colony (CRC170519-01), we observed a male wasp of Mimopriella sp. (deposited in the RMMA collection) emerge on May 19 ${ }^{\text {th }}$, 2017, and a female 10 days later. The live colony had characteristically black larvae when collected. While some natural history has been documented, there is still much more to be discovered about the symbionts, nest architecture, and general biology of M. zeteki. well-studied cryptic species that has been confused with $M$. zeteki for decades. We accomplished this by examining morphology and morphometrics of all castes, analyzing the behavior of workers, comparing worker volatile compounds, and comparing DNA sequence data.

Peer) reviewing PDF | (2020:12:56021:1:1:NEW 8 May 2021) 
807 Interestingly, we also determined that the published genome (Nygaard et al., 2016) belongs to 808 the newly described species M. mikromelanos. Our results underscore the importance of species 809 discovery by emphasizing the value of an integrative taxonomic approach, the effect of species 810 delineation on biodiversity, and the necessity of properly vouchered specimens.

811 While historical taxonomic work generally relied on morphological characters alone to delineate 812 and typify species, modern taxonomy more often utilizes other biological evidence (Dayrat, 813 2005; Schlick-Steiner et al., 2010). An integrative approach is frequently used to overcome the 814 challenges of cryptic species, especially those lacking clear morphological characters adequate 815 for recognizing species boundaries. Complementary lines of evidence in addition to morphology 816 (e.g., behavioral, molecular, chemical, ecological, etc.) increase our confidence in species 817 descriptions and reveal the intricacies of those species' biology (Dayrat, 2005). Employing this 818 approach, we analyzed biologically relevant evidence along with key morphological 819 characters - summarized in the diagnoses of M. mikromelanos and M. zeteki-that proved useful 820 for distinguishing the two species. These are best observed using a standard dissection 821 microscope but can also be detected with a 20X loupe. Another line of evidence is provided by 822 our behavioral analysis. It was initially assumed that tempo would reflect behavioral differences 823 observed in the field, where M. zeteki appeared 'aggressive' and M. mikromelanos 'passive'. 824 However, we found that these two sibling species show differences in tempo, the rate of 825 movement, rather than in aggressive or passive behaviors. Lastly, our chemical analysis also 826 shows species-specific differences in the abundance of volatile compounds for most analyzed 827 workers of both species. The combined evidence supports the existence of two distinct and 828 closely related sympatric species in the Panama Canal Zone, M. mikromelanos and M. zeteki.

829 The recognition of two species adds to our understanding of the multiple symbiotic relationships 830 involving each species. It should be noted that, although it appears fairly certain that $M$.

831 mikromelanos represents a single, well-supported species (Fig. 1e), the possibility remains that 832 M. zeteki as currently defined may actually consist of two or more cryptic species. In Fig. 1e, all 833 the samples of $M$. mikromelanos form a very well-supported clade whereas the monophyly of the 834 two M. zeteki samples is poorly supported. This is also reflected in a larger phylogeny where the 835 same two $M$. zeteki samples are monophyletic but have similarly poor support and long branch 836 lengths (see Fig. 2 of Solomon et al., 2019).

837 Species delimitation is essential not only for descriptive biology, but also for understanding the 838 levels of biodiversity. In this context, species represent units of study that help us comprehend 839 ecological and evolutionary principals. These include, but are not limited to, genetic diversity, 840 adaptation, and broad-scale community interactions. Fungus-growing ants are an intriguing 841 group for the study of biodiversity given their coevolutionary history with their fungal cultivars 842 (Mehdiabadi et al., 2012), their many other symbiotic relationships (Mueller, Rehner \& Schultz, 843 1998; Currie, Mueller \& Malloch, 1999; De Fine Licht \& Boomsma, 2014), and the role fungus844 growing ants play as ecosystem engineers (Jones, Lawton \& Shachak, 1994; Folgarait, 1998; 845 Meyer et al., 2011, 2013). However, the distributions and ecological roles of most non-leaf846 cutting attines in neotropical environments is still poorly studied (but see Leal \& Oliveira 2000; 
847 Vasconcelos et al., 2008; Tschinkel \& Seal, 2016). For example, during the summer of 2018 we

848 searched BCI, Fort Sherman, and El Llano (ca. 15, 35, and $80 \mathrm{~km}$ from Pipeline Road,

849 respectively) for both $M$. mikromelanos and $M$. zeteki. Yet after searching kilometers of trails

850 and creeks on BCI we were unable to locate any M. mikromelanos colonies, and only located two

851 M. zeteki colonies on BCI and one at El Llano. No M. mikromelanos were found outside of the

852 regularly sampled Gamboa Forest and Pipeline Road areas with the exception of a sample

853 collected by Dr. Jack Longino in the Darien Provence of Panama in 2015. Regardless of our

854 uncertainty of M. mikromelanos' distribution outside of the Canal Zone, we do have some

855 familiarity with M. mikromelanos' and M. zeteki's symbiotic associations. For example, they

856 maintain similar relationships with social parasites, garden pathogens, and parasitoids (see

857 "Biology" in species descriptions). Describing M. mikromelanos has enhanced our understanding

858 of the symbiotic relationships of both species and raises more questions about them and their

859 associates. Further research clarifying the natural history of these species and their symbionts

860 will help us discern their ecological roles and contribute to our understanding of biodiversity in

861 the Panama Canal Zone.

862 Genetic patterns and genetic diversity are another important aspect of biodiversity. Together they

863 can inform understanding of the dispersal capabilities of species (Sanetra \& Crozier, 2003;

864 Sanllorente, Ruano \& Tinaut, 2015; Boulay et al., 2017; Helms, 2018) biogeographic histories

865 (Branstetter et al., 2017; Mueller et al., 2017, 2018), demographic history (Castilla et al., 2016),

866 and evolutionary patterns (Baer \& Boomsma, 2004; Schultz \& Brady, 2008; Nygaard et al.,

867 2016; Mueller et al., 2018). Modern molecular genetic tools enable researchers to study

868 populations and their patterns at broad biogeographic ranges. For example, higher attine ants

869 grow two clades of fungi according to several studies (Solomon et al., 2019; Schultz et al., 2015;

870 Ješovnik et al., 2017; Shik et al., 2021; Mueller et al., 2018). Still, there is not a one-to-one

871 association or complete phylogenetic congruence between higher attine ants and their cultivars

872 (Schultz et al., 2015; Mueller et al., 2018). Including a broader sampling of species revealed that

873 a lower attine species (e.g., Apterostigma megacephala Lattke, 1999) also cultivates a $L$.

874 gongylophorus higher attine garden (Schultz et al., 2015). Furthermore, multiple cultivar strains

875 or haplotypes can be cultivated by the same or different ant species from the same location

876 (Green, Mueller \& Adams, 2002; Shik et al., 2021). As in most scientific endeavors, new

877 knowledge of ant-fungus associations requires constant updating of older models (Chapela et al.,

878 1994; Mueller \& Wcislo, 1998; Schultz \& Brady, 2008; Mehdiabadi \& Schultz, 2010). This

879 process generates a deeper and more complicated picture of the biogeographic patterns observed

880 in populations of the higher attines. Well-designed population-level analyses of the 61 non-leaf-

881 cutting higher attine ant species (e.g., Mycetomoellerius, Paratrachymyrmex, Trachymyrmex,

882 Xerolitor, and Sericomyrmex) would further refine our understanding of coevolution in the

883 fungus-growing ants. Mycetomoellerius mikromelanos is well suited for such population-genetic

884 analyses for a few reasons: it is abundant in the Canal Zone and easily located given its

885 characteristic auricle nest entrance, it is sympatric with its sister species M. zeteki, and it has a

886 published genome (Nygaard et al., 2016). Originally named Trachymyrmex zeteki on GenBank

Peer] reviewing PDF | (2020:12:56021:1:1:NEW 8 May 2021) 
887 (Nygaard et al., 2016; GenBank accession: GCA_001594055.1), we confirm in this study based 888 on published nuclear gene sequences (see phylogenetic analysis) and morphological evidence of 889 vouchers (see taxonomy; Figs. S11 \& S12) that it is the genome of M. mikromelanos.

890 The published genome of M. mikromelanos highlights the importance of species identification 891 and voucher specimen deposition. Physical vouchers provide reproducibility and confidence in 892 published findings. Curating physical collections, naming species, and creating molecular 893 databases still depend on non-molecular taxonomic work (Dayrat, 2005; Turney et al., 2015). We 894 found that the incidence of reported vouchering for M. zeteki or M. cf. zeteki, based on our 895 literature review, is higher than what is typically found in the field of entomology (44\% versus 896 35\%: Turney et al., 2015). This could be due to the exponential increase in research focusing on

897

898

899

900

901

902

903

904

905

906

907

908

909

910

911

912

913

914

915

916

917

918

919

920

921

922

923

924 attines and collaborations with skilled taxonomists over the past thirty to forty years. We argue that more effort in voucher deposition is needed and that this is especially true when genomic information is published. Genomic resources are frequently used to compare and characterize gene functions (e.g., Lee et al., 2017; Nolasco et al., 2018; Wang et al., 2019). Incomplete taxonomic information can lead to a series of misguided future studies.

\section{Conclusions}

Given the abundance of M. mikromelanos in the Panama Canal Zone, we expect that the majority of researchers who believe they have studied M. zeteki have studied M. mikromelanos instead (Appendix Table 1). We encourage these researchers to mount specimens, confirm the species identification, and deposit the vouchers in a well-curated and accessible natural history museum collection. Our hope is that our results will encourage voucher deposition, even for common species such as M. mikromelanos. While physical voucher specimens are not typically required by journal policy or by reviewers (Turney et al., 2015), our findings draw attention to why this is important. We recommend that investigators include voucher specimen preparation and deposition as part of their normal research practice and instill this principle in mentees and colleagues.

\section{Acknowledgements}

We thank the staff and researchers at the Smithsonian Tropical Research Institute (STRI) for logistical support and the Autoridad Nacional del Ambiente y el Mar for permission to sample and export ants. Some live colonies were provided by our colleague Morten Schiøtt, along with Matt F. Fisher and Konstantinos Giampoudakis in conjunction with the graduate course Tropical Behavioral Ecology and Evolution (TBEE) at STRI, hosted by the Centre for Social Evolution, University of Copenhagen and STRI in 2011 and by The Ohio State University and STRI in 2017 and 2019. Specimens were generously loaned from the Museum of Comparative Zoology, Harvard, Cambridge, Massachusetts, the National Museum of Natural History, Washington, D.C., The Natural History Museum Basel, Basel, Switzerland, and Jack Longino. We thank Panagiotis Sapountzis for assistance with the etymology, Luciana Musetti and Sarah Hemly from the Triplehorn Insect Collection, and David Culver, Joan M. Herbers, and Steven Passoa for 
925 microscopy support. We thank Alexander Wild for assistance with establishing an Adams Mega. 926 Lab automontage system. We are grateful to Christopher Wilson, Marymegan Daly, and the 927 Adams Mega Ant Lab peers for improving this work with extensive editing, conversation, and 928 encouragement. We thank the Reviewers Pepijn Kooij, Rodrigo Feitosa, and Monica Ulyssea 929 and the editor Joeseph Gillespie for helpful comments on the final draft of the manuscript. 930 Lastly, we dedicate this work to the late Christopher Wilson, who will be missed.

\section{References}

932

933

934

935

936

937

938

939

940

941

942

943

944

945

946

947

948

949

950

951

952

953

954

955

956

957

958

959

960

961

962

963

964

965

966

967

968

969

Adams RMM, Jones TH, Jeter AW. 2010. Male specific tyramides from three additional myrmicine genera. Biochemical Systematics and Ecology 38:454-456. DOI: 10.1016/j.bse.2010.03.008.

Adams RMM, Jones TH, Jeter AW, De Fine Licht HH, Schultz TR, Nash DR. 2012a. A comparative study of exocrine gland chemistry in Trachymyrmex and Sericomyrmex fungus-growing ants. Biochemical Systematics and Ecology 40:91-97. DOI: 10.1016/j.bse.2011.10.011.

Adams RMM, Liberti J, Illum AA, Jones TH, Nash DR, Boomsma JJ. 2013. Chemically armed mercenary ants protect fungus-farming societies. Proceedings of the National Academy of Sciences 110:15752-15757. DOI: 10.1073/pnas.1311654110.

Adams RMM, Shah K, Antonov LD, Mueller UG. 2012b. Fitness consequences of nest infiltration by the mutualist-exploiter Megalomyrmex adamsae. Ecological Entomology 37:453-462. DOI: 10.1111/j.1365-2311.2012.01384.x.

Altschul SF, Gish W, Miller W, Myers EW, Lipman DJ. 1990. Basic local alignment search tool. Journal of Molecular Biology 215:403-410. DOI: 10.1016/S0022-2836(05)80360-2.

Baer B, Boomsma JJ. 2004. Male reproductive investment and queen mating-frequency in fungus-growing ants. Behavioral Ecology 15:426-432. DOI: 10.1093/beheco/arh025.

Bates D, Mächler M, Bolker B, Walker S. 2015. Fitting linear mixed-effects models using lme4. Journal of Statistical Software 67:1-48. DOI: 10.18637/jss.v067.i01.

Beshers SN, Traniello JFA. 1996. Polyethism and the adaptiveness of worker size variation in the attine ant Trachymyrmex septentrionalis. Journal of Insect Behavior. DOI: 10.1007/BF02213724.

Boomsma JJ. 2007. Kin selection versus sexual selection: Why the ends do not meet. Current Biology 17:673-683. DOI: 10.1016/j.cub.2007.06.033.

Boudinot BE, Sumnicht TP, Adams RMM. 2013. Central American ants of the genus Megalomyrmex Forel (Hymenoptera: Formicidae): six new species and keys to workers and males. Zootaxa 3732:1-82. DOI: 10.11646/zootaxa.3732.1.1

Boulay R, Aron S, Cerdá X, Doums C, Graham P, Hefetz A, Monnin T. 2017. Social life in arid environments: The case study of Cataglyphis ants. Annual Review of Entomology 62:305321. DOI: 10.1146/annurev-ento-031616-034941.

Brandão CRF, Mayhé-Nunes AJ. 2007. A phylogenetic hypothesis for the Trachymyrmex species groups, and the transition from fungus-growing to leaf-cutting in the Attini. Memoirs of the American Entomological Institut 80:73-87. DOI: 10.1533/9781845696382.2.267.

Branstetter MG, Ješovnik A, Sosa-calvo J, Lloyd MW, Faircloth BC, Brady SGS, Schultz TR. 2017. Dry habitats were crucibles of domestication in the evolution of agriculture in ants. Proceedings of the Royal Society B: Biological Sciences 284:1-10. DOI: 10.1098/rspb.2017.0095.

Cafaro MJ, Currie CR. 2005. Phylogenetic analysis of mutualistic filamentous bacteria

Peer) reviewing PDF | (2020:12:56021:1:1:NEW 8 May 2021) 
970

971

972

973

974

975

976

977

978

979

980

981

982

983

984

985

986

987

988

989

990

991

992

993

994

995

996

997

998

999

1000

1001

1002

1003

1004

1005

1006

1007

1008

1009

1010

1011

1012

1013

1014

1015

associated with fungus-growing ants. Canadian journal of microbiology 51:441-446. DOI: 10.1139/w05-023.

Cardenas CR, DeMilto AD, Schultz TR, Adams RMM. 2016. A revisionary study of Trachymyrmex zeteki (Formicidae: Attini) and description of a new species, Trachymyrmex fovater sp. n. In: The Ohio State University 2016 Fall Undergraduate Poster Forum, 10th. Columbus, OH: Knowledge Bank.

Castilla AR, Pope N, Jaffé R, Jha S. 2016. Elevation, not deforestation, promotes genetic differentiation in a pioneer tropical tree. PloS ONE 11:1-22. DOI: 10.1371/journal.pone.0156694.

Chapela I, Rhener S, Schultz TR, Mueller UG. 1994. Evolutionary history of the symbiosis between fungus-growing ants and their fungi. Science 266:1691-1694.

Chapman BB, Thain H, Coughlin J, Hughes WOH. 2011. Behavioural syndromes at multiple scales in Myrmica ants. Animal Behaviour 82:391-397. DOI: 10.1016/j.anbehav.2011.05.019.

Cristiano MP, Cardoso DC, Sandoval-Gómez VE, Simões-Gomes FC. 2020. Amoimyrmex Cristiano, Cardoso, \& Sandoval, gen. nov. (Hymenoptera: Formicidae): a new genus of leaf-cutting ants revealed by multilocus molecular phylogenetic and morphological analyses. Austral Entomology. 59:643-676. DOI: 10.1111/aen.12493

Currie CR, Mueller UG, Malloch D. 1999. The agricultural pathology of ant fungus gardens. Proceedings of the National Academy of Sciences of the United States of America 96:79988002.

Currie CR, Wong B, Stuart AE, Schultz TR, Rehner SA, Mueller UG, Sung GH, Spatafora JW, Straus NA. 2003. Ancient tripartite coevolution in the attine ant-microbe symbiosis. Science 299:386-388. DOI: 10.1126/science.1078155.

Dayrat B. 2005. Towards integrative taxonomy. Biological Journal of the Linnean Society 85:407-415. DOI: 10.1111/j.1095-8312.2005.00503.x.

De Fine Licht HH, Boomsma JJ. 2010. Forage collection, substrate preparation, and diet composition in fungus-growing ants. Ecological Entomology 35:259-269. DOI: 10.1111/j.1365-2311.2010.01193.x.

De Fine Licht HH, Boomsma JJ. 2014. Variable interaction specificity and symbiont performance in Panamanian Trachymyrmex and Sericomyrmex fungus-growing ants. BMC evolutionary biology 14:1-10. DOI: 10.1186/s12862-014-0244-6.

Folgarait PJ. 1998. Ant biodiversity and its relationship to ecosystem functioning: a review. Biodiversity and Conservation 7:1221-1244. DOI: 10.1023/A:1008891901953.

Forel A-H. 1893. Note sur les Attini. Annales de la Société Entomologique Belge 37:586-607.

Green AM, Mueller UG, Adams RMM. 2002. Extensive exchange of fungal cultivars between sympatric species of fungus-growing ants. Molecular Ecology 11:191-195. DOI: 10.1046/j.1365-294X.2002.01433.x.

Glon MG, Thoma RF, Daly M, Freudenstein JV. 2019. Lacunicambarus chimera: a new species of burrowing crayfish (Decapoda: Cambaridae) from Illinois, Indiana, Kentucky, and Tennessee. Zootaxa 4544(4):451-478.

Hamilton N, Jones TH, Shik JZ, Wall B, Schultz TR, Blair HA, Adams RMM. 2018. Context is everything: mapping Cyphomyrmex-derived compounds to the fungus-growing ant phylogeny. Chemeocology 28:137-144. DOI: 10.1007/s00049-018-0265-5

Harris RA. 1979. A glossary of surface sculpturing. Occasional Papers in Entomology 28:1-34. DOI: $10.5281 /$ zenodo.26215. 
1016 Helms JAI. 2018. The flight ecology of ants (Hymenoptera: Formicidae). Myrmecological News

1017

1018

1019

1020

1021

1022

1023

1024

1025

1026

1027

1028

1029

1030

1031

1032

1033

1034

1035

1036

1037

1038

1039

1040

1041

1042

1043

1044

1045

1046

1047

1048

1049

1050

1051

1052

1053

1054

1055

1056

1057

1058

1059

1060

1061 26:19-30.

Helms JA, Peeters C, Fisher BL. 2014. Funnels, gas exchange and cliff jumping: Natural history of the cliff dwelling ant Malagidris sofina. Insectes Sociaux 61:357-365. DOI:

10.1007/s00040-014-0360-8.

Hoang DT, Chernomor O, von Haeseler A, Minh BQ, Vinh LS. 2018. UFBoot2: improving the ultrafast bootstrap approximation. Molecular Biology and Evolution 35:518-522. DOI: 10.5281 /zenodo.854445.

International Commission on Zoological Nomenclature. 1999. International code of zoological nomenclature. London: The International Trust for Zoological Nomenclature.

Ješovnik A, Schultz TR. 2017. Revision of the fungus-farming ant genus Sericomyrmex Mayr (Hymenoptera, Formicidae, Myrmicinae). ZooKeys 670:1-109. DOI: 10.3897/zookeys.670.11839.

Ješovnik A, Sosa-calvo J, Lopes CT, Vasconcelos HL, Schultz TR. 2013. Nest architecture, fungus gardens, queen, males and larvae of the fungus-growing ant Mycetagroicus inflatus Brandão \& Mayhé-Nunes. Insectes Sociaux 60:531-542. DOI: 10.1007/s00040-013-0320-8.

Jones CG, Lawton JH, Shachak M. 1994. Organisms as ecosystem engineers. Oikos 69:373-386. DOI: $10.2307 / 3545850$.

Kalyaanamoorthy S, Minh BQ, Wong TKF, Von Haeseler A, Jermiin LS. 2017. ModelFinder: fast model selection for accurate phylogenetic estimates. Nature Methods 14:587-589. DOI: 10.1038/nmeth.4285.

Lattke JE. 1999. A new species of fungus-growing ant and its implications for attine phylogeny (Hymenoptera: Formicidae). Systematic Entomology 24:1-6.

Leal IR, Oliveira PS. 2000. Foraging ecology of attine ants in a Neotropical savanna: seasonal use of fungal substrate in the cerrado vegetation of Brazil. Insectes Sociaux 47:376-382. DOI: $10.1007 /$ PL00001734.

Lee J, Suryaningtyas IT, Yoon T, Min J, Park H, Kim H. 2017. Transcriptomic analysis of the hepatopancreas induced by eyestalk ablation in shrimp, Litopenaeus vannamei. Comparative Biochemistry and Physiology - Part D 24:99-110. DOI: 10.1016/j.cbd.2017.08.004.

Little AEF, Murakami T, Mueller UG, Currie CR. 2003. The infrabuccal pellet piles of fungusgrowing ants. Die Naturwissenschaften 90:558-562. DOI: 10.1007/s00114-003-0480-X.

Little AEF, Murakami T, Mueller UG, Currie CR. 2006. Defending against parasites: fungusgrowing ants combine specialized behaviours and microbial symbionts to protect their fungus gardens. Biology Letters 2:12-16. DOI: doi:10.1098/rsbl.2005.0371.

Lizidatti CS. 2006. Biologia, arquitetura de ninhos e coleta de substratos no Cerrado por formigas cultivadoras de fungo, Trachymyrmex holmgreni Wheeler 1925 (Hymenoptera, Formicidae, Attini). Universidade Estadual Paulista.

Longino JT. 2005. Complex nesting behavior by two Neotropical species of the ant genus Stenamma (Hymenoptera: Formicidae). Biotropica 37:670-675.

Longino JT. 2010. A taxonomic review of the ant genus Megalomyrmex Forel (Hymenoptera: Formicidae) in Central America. Zootaxa 2720:35-58. DOI: 10.11646/zootaxa.2720.1.3

Masner L, García JR. 2002. The genera of Diapriinae (Hymenoptera: Diapriidae) in the New World. Bulletin of the American Museum of Natural History 268:1-138. DOI: 10.1206/0003-0090(2002)268<0001:TGODHD>2.0.CO;2.

Mayhé-Nunes AJ, Brandão CRF. 2002. Revisionary studies on the Attine ant genus

Peer) reviewing PDF | (2020:12:56021:1:1:NEW 8 May 2021) 
1062

1063

1064

1065

1066

1067

1068

1069

1070

1071

1072

1073

1074

1075

1076

1077

1078

1079

1080

1081

1082

1083

1084

1085

1086

1087

1088

1089

1090

1091

1092

1093

1094

1095

1096

1097

1098

1099

1100

1101

1102

1103

1104

1105

1106

1107

Trachymyrmex Forel. Part 1: definition of the genus and the Opulentus group (Hymenoptera: Formicidae). Sociobiology 40:667-698. DOI: 10.1111/j.17447429.2005.00085.x

Mayhé-Nunes AJ, Brandão CRF. 2005. Revisionary studies on the Attine ant genus

Trachymyrmex Forel. Part 2: the Iheringi group (Hymenoptera: Formicidae). Sociobiology 45:271-305.

Mayhé-Nunes AJ, Brandão CRF. 2007. Revisionary studies on the attine ant genus

Trachymyrmex Forel. Part 3: the Jamaicensis group (Hymenoptera: Formicidae). Zootaxa 1444:1-21.

Mayr G. 1865. Formicidae. In: Novara Expedition 1865. Reise der Österreichischen Fregatte "Novara" um die Erde in den Jahren 1857, 1858, 1859. Zoologischer Theil. Bd. II. Abt. 1. Wein: K. Gerol's Son, 83.

McCune B, Grace JB. 2002. Analysis of ecological communities. Gleneden Beach, Oregon USA: MjM Software Design.

Mehdiabadi NJ, Mueller UG, Brady SG, Himler AG, Schultz TR. 2012. Symbiont fidelity and the origin of species in fungus-growing ants. Nature Communications 3:1-7. DOI: $10.1038 /$ ncomms 1844.

Mehdiabadi NJ, Schultz TR. 2010. Natural history and phylogeny of the fungus-farming ants (Hymenoptera: Formicidae: Myrmicinae: Attini). Myrmecological News 13:37-55.

Meyer ST, Leal IR, Tabarelli M, Wirth R. 2011. Ecosystem engineering by leaf-cutting ants: nests of Atta cephalotes drastically alter forest structure and microclimate. Ecological Entomology 36:14-24. DOI: 10.1111/j.1365-2311.2010.01241.x.

Meyer ST, Neubauer M, Sayer EJ, Leal IR, Tabarelli M, Wirth R. 2013. Leaf-cutting ants as ecosystem engineers: topsoil and litter perturbations around Atta cephalotes nests reduce nutrient availability. Ecological Entomology 38:497-504. DOI: 10.1111/een.12043.

Muchovej JJ, Della Lucia TMC. 1990. Escovopsis, a new genus from leaf cutting ant nests to replace Phialocladus nomen invalidum. Mycotaxa 37:191-195

Morgulis A, Coulouris G, Raytselis Y, Madden TL, Agarwala R, Schäffer AA. 2008. Database indexing for production MegaBLAST searches. Bioinformatics 24:1757-1764. DOI: 10.1093/bioinformatics/btn322.

Mueller UG, Dash D, Rabeling C, Rodrigues A. 2008. Coevolution between attine ants and actinomycete bacteria: a reevaluation. Evolution 62:2894-2912. DOI: 10.1111/j.15585646.2008.00501.x.

Mueller UG, Ishak HD, Bruschi SM, Smith CC, Herman JJ, Solomon SE, Mikheyev AS, Rabeling C, Scott JJ, Cooper M, Rodrigues A, Ortiz A, Brandão CRF, Lattke JE, Pagnocca FC, Rehner SA, Schultz TR, Vasconcelos HL, Adams RMM, Bollazzi M, Clark RM, Himler AG, LaPolla JS, Leal IR, Johnson RA, Roces F, Sosa-Calvo J, Wirth R, Bacci M. 2017. Biogeography of mutualistic fungi cultivated by leafcutter ants. Molecular Ecology 26:6921-6937. DOI: 10.1111/mec.14431.

Mueller UG, Kardish MR, Ishak HD, Wright AM, Solomon SE, Bruschi SM, Carlson AL, Bacci M. 2018. Phylogenetic patterns of ant-fungus associations indicate that farming strategies, not only a superior fungal cultivar, explain the ecological success of leafcutter ants. Molecular Ecology 27:2414-2434. DOI: 10.1111/mec.14588.

Mueller UG, Rehner SA, Schultz TR. 1998. The evolution of agriculture in ants. Science 281:2034-2038. DOI: 10.1126/science.281.5385.2034.

Mueller UG, Wcislo WT. 1998. Nesting biology of the fungus-growing ant Cyphomyrmex

Peer) reviewing PDF | (2020:12:56021:1:1:NEW 8 May 2021) 
1108

1109

1110

1111

1112

1113

1114

1115

1116

1117

1118

1119

1120

1121

1122

1123

1124

1125

1126

1127

1128

1129

1130

1131

1132

1133

1134

1135

1136

1137

1138

1139

1140

1141

1142

1143

1144

1145

1146

1147

1148

1149

1150

1151

1152

1153

longiscapus Weber (Attini, Formicidae). Insectes Sociaux 45:181-189.

Nguyen LT, Schmidt HA, Von Haeseler A, Minh BQ. 2015. IQ-TREE: a fast and effective stochastic algorithm for estimating maximum-likelihood phylogenies. Molecular Biology and Evolution 32:268-274. DOI: 10.1093/molbev/msu300.

Nolasco M, Biondi I, Pimenta DC, Branco A. 2018. Extraction and preliminary chemical characterization of the venom of the spider wasp Pepsis decorata (Hymenoptera : Pompilidae ). Toxicon 150:74-76. DOI: 10.1016/j.toxicon.2018.04.023.

Nygaard S, Hu H, Li C, Schiøtt M, Chen Z, Yang Z, Xie Q, Ma C, Deng Y, Dikow R, Rabeling C, Nash DR, Wcislo WT, Brady SG, Schultz TR, Zhang G, Boomsma JJ. 2016. Reciprocal genomic evolution in the ant-fungus agricultural symbiosis. Nature communications 7:1-9. DOI: $10.1038 /$ ncomms 12233 .

Oksanen J, Blanchet FG, Friendly M, Kindt R, Legendre P, McGlinn D, Minchin PR, O'Hara RB, Simpson GL, Solymos P, Stevens MHH, Szoecs E, Wagner H. 2019. vegan: community ecology package. Available at https://github.com/vegandevs/vegan

Pérez-Ortega B, Fernández-Marín H, Loiácono MS, Galgani P, Wcislo WT. 2010. Biological notes on a fungus-growing ant, Trachymyrmex cf. zeteki (Hymenoptera, Formicidae, Attini) attacked by a diverse community of parasitoid wasps (Hymenoptera, Diapriidae). Insectes Sociaux 57:317-322. DOI: 10.1007/s00040-010-0086-1.

Persoon CH. 1794. Neuer Versuch einer systematischen Eintheilung der Schwämme. Neues Magazin für die Botanik. 1:63-80.

Péter A. 2017. Solomon Coder. Available at https://solomon.andraspeter.com/

R Core Team. 2017. R: A language and environment for statistical computing. Availble at https://www.r-project.org/

Rabeling C, Cover SP, Johnson RA, Mueller UG, Robert J, Mueller UG. 2007. A review of the North American species of the fungus-gardening ant genus Trachymyrmex (Hymenoptera: Formicidae). Zootaxa 53:1-53. DOI: 10.11646/zootaxa.1664.1.1.

Rabeling C, Schultz TR, Bacci M, Bollazzi M. 2015. Acromyrmex charruanus: a new inquiline social parasite species of leaf-cutting ants. Insectes Sociaux 62:335-349. DOI: 10.1007/s00040-015-0406-6.

Rambaut A. 2016. FigTree. Available at https://github.com/rambaut/figtree/releases

Ronque MUV, Feitosa RM, Oliveira PS. 2019. Natural history and ecology of fungus-farming ants: a field study in Atlantic rainforest. Insectes Sociaux 66:375-387. DOI: 10.1007/s00040-019-00695-y.

Sánchez-Peña SR, Chacón-Cardosa MC, Canales-del-Castillo R, Ward L, Resendez-Pérez D. 2017. A new species of Trachymyrmex (Hymenoptera, Formicidae) fungus-growing ant from the Sierra Madre Oriental of northeastern Mexico. ZooKeys 2017:73-94. DOI: 10.3897/zookeys.706.12539.

Sanetra M, Crozier RH. 2003. Patterns of population subdivision and gene flow in the ant Nothomyrmecia macrops reflected in microsatellite and mitochondrial DNA markers. Molecular Ecology 12:2281-2295. DOI: 10.1046/j.1365-294X.2003.01900.x.

Sanllorente O, Ruano F, Tinaut A. 2015. Large-scale population genetics of the mountain ant Proformica longiseta (Hymenoptera: Formicidae). Population Ecology 57:637-648. DOI: 10.1007/s10144-015-0505-2.

Schlick-Steiner BC, Steiner FM, Seifert B, Stauffer C, Christian E, Crozier RH. 2010. Integrative taxonomy: a multisource approach to exploring biodiversity. Annual Review of Entomology 55:421-438. DOI: 10.1146/annurev-ento-112408-085432.

Peer) reviewing PDF | (2020:12:56021:1:1:NEW 8 May 2021) 
1154

1155

1156

1157

1158

1159

1160

1161

1162

1163

1164

1165

1166

1167

1168

1169

1170

1171

1172

1173

1174

1175

1176

1177

1178

1179

1180

1181

1182

1183

1184

1185

1186

1187

1188

1189

1190

1191

1192

1193

1194

1195

1196

1197

1198

1199

Schultz TR, Bekkevold D, Boomsma JJ. 1998. Acromyrmex insinuator new species: an incipient social parasite of fungus-growing ants. Insectes Sociaux 45:457-471. DOI: 10.1007/s000400050101.

Schultz TR, Brady SG. 2008. Major evolutionary transitions in ant agriculture. Proceedings of the National Academy of Sciences 105:5435-5440. DOI: 10.1073/pnas.0711024105.

Schultz TR, Meier R. 1995. A phylogenetic analysis of the fungus-growing ants (Hymenoptera: Formicidae: Attini) based on morphological characters of the larvae. Systematic Entomology 20:337-370. DOI: 10.1111/j.1365-3113.1995.tb00100.x.

Schultz TR, Solomon SA, Mueller UG, Villesen P, Boomsma JJ, Adams RMM, Norden B. 2002. Cryptic speciation in the fungus-growing ants Cyphomyrmex longiscapus Weber and Cyphomyrmex muelleri Schultz and Solomon, new species (Formicidae, Attini). Insectes Sociaux 49:331-343. DOI: 10.1007/PL00012657.

Schultz TR, Sosa-Calvo J, Brady SG, Lopes CT, Mueller UG, Bacci M, Vasconcelos HL. 2015. The most relictual fungus-farming ant species cultivates the most recently evolved and highly domesticated fungal symbiont species. The American Naturalist 185:693-703. DOI: 10.1086/680501

Shik JZ, Kooij PW, Donoso DA, Santos JC, Gomez EB, Franco M, Crumière AJJ, Arnan X, Howe J, Wcislo WT, Boomsma JJ. 2021. Nutritional niches reveal fundamental domestication trade-offs in fungus-farming ants. Nature Ecology and Evolution 5:122-134. DOI: 10.1038/s41559-020-01314-X.

Simon C, Frati F, Beckenbach A, Crespi B, Liu H, Flook P. 1994. Evolution, weighting, and phylogenetic utility of mitochondrial gene sequences and a compilation of conserved polymerase chain reaction primers. Annals of the Entomological Society of America 87:651-701. DOI: 10.1093/aesa/87.6.651.

Singer R. 1986. The Agaricales in modern taxonomy. Koenigstein, Federal Republic of Germany: Koeltz Scientific Books.

Solomon SE, Rabeling C, Sosa-Calvo J, Lopes CT, Rodrigues A, Vasconcelos HL, Bacci M, Mueller UG, Schultz TR. 2019. The molecular phylogenetics of Trachymyrmex Forel ants and their fungal cultivars provide insights into the origin and coevolutionary history of 'higher-attine' ant agriculture. Systematic Entomology 44:939-956. DOI:

10.1111/syen.12370.

Sosa-Calvo J, Ješovnik A, Okonski E, Schultz TR. 2015. Locating, collecting, and maintaining colonies of fungus-farming ants (Hymenoptera: Myrmicinae: Attini). Sociobiology 62:300320. DOI: 10.13102/sociobiology.v62i2.300-320.

Sosa-Calvo J, Ješovnik A, Vasconcelos HL, Bacci M, Schultz TR. 2017. Rediscovery of the enigmatic fungus-farming ant "Mycetosoritis" asper Mayr (Hymenoptera: Formicidae): implications for taxonomy, phylogeny, and the evolution of agriculture in ants. PLOS ONE 12:1-29. DOI: 10.1371/journal.pone.0176498.

Sosa-Calvo J, Schultz TR. 2010. Three remarkable new fungus-growing ant species of the genus Myrmicocrypta (Hymenoptera: Formicidae), with a reassessment of the characters that define the genus and its position within the attini. Annals of the Entomological Society of America 103:181-195. DOI: 10.1603/AN09108.

Sosa-Calvo J, Schultz TR, Ješovnik A, Dahan RA, Rabeling C. 2018. Evolution, systematics, and natural history of a new genus of cryptobiotic fungus-growing ants. Systematic Entomology 43:549-567. DOI: 10.1111/syen.12289.

Tschinkel WR, Seal JN. 2016. Bioturbation by the fungus-gardening ant, Trachymyrmex

Peer) reviewing PDF | (2020:12:56021:1:1:NEW 8 May 2021) 
1200

1201

1202

1203

1204

1205

1206

1207

1208

1209

1210

1211

1212

1213

1214

1215

1216

1217

1218

1219

1220

1221

1222

1223

1224

1225

1226

1227

1228

1229

1230

1231

1232

septentrionalis. PLoS ONE 11:1-15. DOI: 10.1371/journal.pone.0158920.

Turney S, Cameron ER, Cloutier CA, Buddle CM. 2015. Non-repeatable science: assessing the frequency of voucher specimen deposition reveals that most arthropod research cannot be verified. PeerJ 3:1-19. DOI: 10.7717/peerj. 1168.

Vaidya G, Lohman DJ, Meier R. 2011. Cladistics multi-gene datasets with character set and codon information. Cladistics 27:171-180.

Vasconcelos HL, Araújo BB, Mayhé-Nunes AJ. 2008. Patterns of diversity and abundance of fungus-growing ants (Formicidae: Attini) in areas of the Brazilian Cerrado. Revista Brasileira de Zoologia 25:445-450. DOI: 10.1590/S0101-81752008000300009.

Villesen P, Murakami T, Schultz TR, Boomsma JJ. 2002. Identifying the transition between single and multiple mating of queens in fungus-growing ants. Proceedings of the Royal Society London B Biology 269:1541-8. DOI: 10.1098/rspb.2002.2044.

Wang Y, Wang B, Shao X, Shao J, Liu M, Wang M, Wang L. 2019. The effect of rearing density on immune responses of hepatopancreas and intestine in Litopenaeus vananmei against Vibrio paraheamolyticus E1 challenge. Fish and Shellfish Immunology 93:517-530. DOI: 10.1016/j.fsi.2019.08.004.

Ward PS, Brady SG, Fisher BL, Schultz TR. 2015. The evolution of myrmicine ants: phylogeny and biogeography of a hyperdiverse ant clade (Hymenoptera: Formicidae). Systematic Entomology 40:61-81. DOI: 10.1111/syen.12090.

Weber NA. 1940. The biology of the fungus-growing ants. Part VI. Key to Cyphomyrmex, new Attini and a new guest ant. Revista de Entomologia, Rio de Janeiro: 11:406-427. DOI: $10.5281 /$ zenodo. 25008 .

Weber NA. 1958a. Evolution in fungus-growing ants. Proceedings of the Tenth International Congress of Entomology 2:459-473.

Weber NA. 1958b. Nomenclatural changes in Trachymyrmex (Hym.: Formicidae, Attini). Entomological News 69:49-55.

Weber NA. 1972. Gardening ants, the attines. Memoirs of the American Philosophical Society 92:1-146.

Wheeler WM. 1903. A decade of Texan Formicidae. Psyche 10:93-111. DOI: $10.1155 / 1903 / 67840$

Zhang Z, Schwartz S, Wagner L, Miller W. 2000. A greedy algorithm for aligning DNA sequences. Journal of Computational Biology 7:203-214. DOI: 10.1089/10665270050081478. 


\section{Table 1 (on next page)}

Acronyms of standard measurements and indices used for morphology and morphometrics.

Eyes are included in HW for males. 


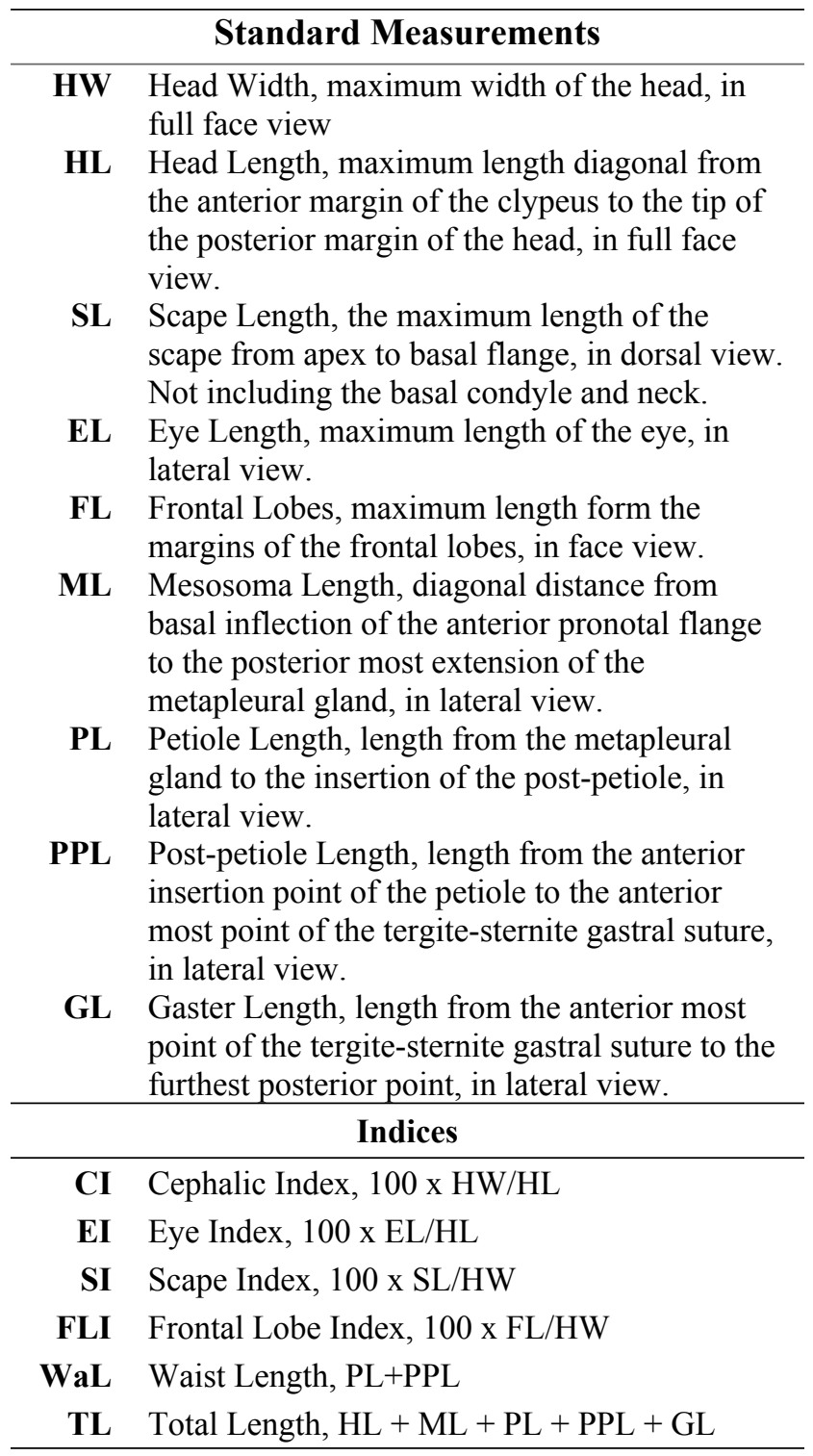

1

2 Table 1 - Acronyms of standard measurements and indices used for morphology and 3 morphometrics. 


\section{Table 2 (on next page)}

Select morphometrics of all castes.

Partitioned mean values, standard errors (SE), minimum and maximum standard measurements in millimeters, except indices (see Table 1) for workers, gynes, and males (cont'd) of M. mikromelanos sp. nov. and M. zeteki. Presented morphometrics were chosen based on vectors from NMDS plots with the most directionality (see Fig. 1a). All Samples except for singleton workers of M. mikromelanos sp. nov. worker (Panama, Darién Provence) and gyne (Costa Rica, Heredia Provence) are from the Panama Canal Zone. 


\begin{tabular}{|c|c|c|c|c|}
\hline $\begin{array}{r}\text { M. mikromelanos sp. } \\
\text { nov. workers } \\
\mathrm{N}=117 \text { (28 nests) }\end{array}$ & Mean & $\mathrm{SE}$ & Min & Max \\
\hline HW & 1.123 & 0.004 & 1.012 & 1.215 \\
\hline EL & 0.201 & 0.001 & 0.165 & 0.230 \\
\hline ML & 1.657 & 0.007 & 1.441 & 1.911 \\
\hline PL & 0.409 & 0.004 & 0.310 & 0.507 \\
\hline $\mathrm{CI}$ & 114.007 & 0.339 & 102.761 & 123.517 \\
\hline SI & 91.829 & 0.226 & 87.792 & 100.194 \\
\hline TL & 4.402 & 0.017 & 3.843 & 4.877 \\
\hline $\begin{array}{r}\text { M. zeteki workers } \\
\mathrm{N}=54 \text { (13 nests) }\end{array}$ & Mean & SE & Min & Max \\
\hline HW & 1.435 & 0.013 & 1.208 & 1.602 \\
\hline EL & 0.256 & 0.002 & 0.207 & 0.286 \\
\hline ML & 1.972 & 0.018 & 1.665 & 2.248 \\
\hline PL & 0.482 & 0.007 & 0.385 & 0.605 \\
\hline $\mathrm{CI}$ & 122.141 & 0.390 & 115.790 & 127.767 \\
\hline SI & 81.329 & 0.311 & 77.441 & 86.661 \\
\hline TL & 5.181 & 0.046 & 4.520 & 6.043 \\
\hline $\begin{array}{r}\text { M. mikromelanos sp. } \\
\text { nov. gynes } \\
\mathrm{N}=25 \text { (9 nests) }\end{array}$ & Mean & $\mathrm{SE}$ & Min & Max \\
\hline HW & 1.298 & 0.005 & 1.267 & 1.380 \\
\hline EL & 0.270 & 0.004 & 0.231 & 0.304 \\
\hline ML & 2.028 & 0.008 & 1.915 & 2.112 \\
\hline PL & 0.599 & 0.010 & 0.507 & 0.704 \\
\hline CI & 113.715 & 0.535 & 104.546 & 119.481 \\
\hline SI & 79.847 & 0.405 & 73.478 & 84.451 \\
\hline TL & 5.659 & 0.018 & 5.435 & 5.814 \\
\hline $\begin{array}{l}\text { M. zeteki gynes } \\
\mathrm{N}=28 \text { (10 nests) }\end{array}$ & Mean & $\mathrm{SE}$ & Min & Max \\
\hline HW & 1.652 & 0.011 & 1.462 & 1.800 \\
\hline EL & 0.378 & 0.003 & 0.333 & 0.399 \\
\hline ML & 2.478 & 0.012 & 2.272 & 2.584 \\
\hline PL & 0.756 & 0.016 & 0.539 & 0.873 \\
\hline $\mathrm{CI}$ & 119.933 & 0.423 & 115.980 & 126.677 \\
\hline SI & 73.602 & 0.255 & 71.111 & 75.923 \\
\hline TL & 6.965 & 0.043 & 6.072 & 7.296 \\
\hline
\end{tabular}

1

2

3

4

5

6

7

8

Table 2 - Select morphometrics of all castes. Partitioned mean values, standard errors (SE), minimum and maximum standard measurements in millimeters, except indices (see Table 1) for workers, gynes, and males (cont'd) of M. mikromelanos sp. nov. and M. zeteki. Presented morphometrics were chosen based on vectors from NMDS plots with the most directionality (see Fig. 1a). All Samples except for singleton workers of $M$. mikromelanos worker (Panama, Darién Provence) and gyne (Costa Rica, Heredia Provence) are from the Panama Canal Zone. 


\begin{tabular}{rcccc}
\hline $\begin{array}{r}\text { M. mikromelanos sp. } \\
\text { nov. males }\end{array}$ & Mean & SE & Min & Max \\
$\mathrm{N}=21$ (5 nests) & & & & \\
\hline HW & 0.840 & 0.004 & 0.817 & 0.893 \\
EL & 0.294 & 0.003 & 0.282 & 0.310 \\
ML & 1.781 & 0.012 & 1.671 & 1.859 \\
PL & 0.369 & 0.006 & 0.338 & 0.437 \\
CI & 122.934 & 0.956 & 115.437 & 134.084 \\
SI & 98.407 & 0.618 & 91.713 & 103.427 \\
TL & 4.550 & 0.035 & 4.196 & 4.759 \\
\hline M. zeteki males & Mean & SE & Min & Max \\
N=22(6 nests) & & & & \\
HW & 1.043 & 0.009 & 0.957 & 1.140 \\
EL & 0.368 & 0.003 & 0.338 & 0.399 \\
ML & 2.015 & 0.020 & 1.830 & 2.168 \\
PL & 0.500 & 0.010 & 0.422 & 0.591 \\
CI & 130.871 & 1.012 & 125.826 & 142.322 \\
SI & 96.988 & 0.822 & 86.822 & 102.687 \\
TL & 5.334 & 0.059 & 4.984 & 5.902 \\
\hline
\end{tabular}

9

10 Table 2 - Continuation

11 


\section{Table 3(on next page)}

Tempo analysis results.

Generalized linear mixed-effects models tested and compared. Each model had 40 observations, 20 each for M. mikromelanos sp. nov. and M. zeteki. Species and constant rows are the fixed effects estimates. Values in parentheses are standard errors (SE) for the cell above. The Gamma Inverse model was the best-fit model based on all diagnostics measures. $* * * p<0.01$. 


\begin{tabular}{rccccc}
\hline & $\begin{array}{c}\text { Linear Mixed } \\
\text { Model }\end{array}$ & $\begin{array}{c}\text { Gaussian } \\
\text { Log-Link }\end{array}$ & $\begin{array}{c}\text { Gamma } \\
\text { Log-Link }\end{array}$ & $\begin{array}{c}\text { Gamma } \\
\text { Identity }\end{array}$ & $\begin{array}{c}\text { Gamma } \\
\text { Inverse }\end{array}$ \\
\hline Species & $-0.593^{* * *}$ & $0.348^{* * *}$ & $0.343^{* * *}$ & $0.203^{* * *}$ & $-0.589^{* * *}$ \\
$(\mathrm{SE})$ & $\left(0.161^{* * *}\right.$ & $(0.116)$ & $(0.101)$ & $(0.055)$ & $(0.181)$ \\
Constant & $2.031^{* * *}$ & $-0.712^{* * *}$ & $-0.709^{* * *}$ & $0.492^{* * *}$ & $2.035^{* * *}$ \\
$(\mathrm{SE})$ & $(0.132)$ & $(0.090)$ & $(0.072)$ & $(0.032)$ & $(0.143)$ \\
Log Likelihood & 8.887 & 12.889 & 14.765 & 14.711 & 14.848 \\
Akaike Inf. Criterion & -9.739 & -17.778 & -21.530 & -21.422 & -21.695 \\
Bayesian Inf. Criterion & -2.983 & -11.023 & -14.774 & -14.667 & -14.940 \\
\hline
\end{tabular}

1

2 Table 3 - Tempo analysis results. Generalized linear mixed-effects models tested and compared. Each model had 40

3 observations, 20 each for M. mikromelanos sp. nov. and M. zeteki. Species and constant rows are the fixed effects

4 estimates. Values in parentheses are standard errors (SE) for the cell above. The Gamma Inverse model was the best-fit

5 model based on all diagnostics measures. $* * * \mathrm{p}<0.01$.

6 


\section{Table 4(on next page)}

Volatile worker compounds.

The average relative amount of 6 M. mikromelanos sp. nov. and $4 M$. zeteki colonies sampled and standard error for compounds found in workers of both species. Worker farnesenes Farn.1: E- $\beta$-farnesene, Farn.2: (3Z,6E)- $\alpha$-farnesene, and Farn.3: (3E,6E)- $\alpha$-farnesene. 


\begin{tabular}{|c|c|c|c|c|}
\hline $\begin{array}{r}\text { Comp } \\
\text { Retention }\end{array}$ & & $\begin{array}{c}\text { Farn.1 } \\
18.27 \\
\end{array}$ & $\begin{array}{r}\text { Farn.2 } \\
18.74 \\
\end{array}$ & $\begin{array}{c}\text { Farn.3 } \\
18.93 \\
\end{array}$ \\
\hline $\begin{array}{r}\text { mikromelanos } \\
\text { sp. nov. } \\
\text { zeteki }\end{array}$ & 4 & $\begin{array}{l}0.133 \\
\pm 0.08 \\
0.622 \\
\pm 0.14\end{array}$ & $\begin{array}{l}0.089 \\
\pm 0.04 \\
0.184 \\
\pm 0.10\end{array}$ & $\begin{array}{l}0.693 \\
\pm 0.13 \\
0.065 \\
\pm 0.01\end{array}$ \\
\hline
\end{tabular}

1

2 Table 4 - Volatile worker compounds. The average relative amount of $6 \mathrm{M}$. mikromelanos sp. 3 nov. and $4 \mathrm{M}$. zeteki colonies sampled and standard error for compounds found in workers of both 4 species. Worker farnesenes Farn.1: E- $\beta$ - farnesene, Farn.2: (3Z,6E)- $\alpha$-farnesene, and Farn.3: 5 (3E,6E)- $\alpha$-farnesene.

6 


\section{Figure 1}

Integrative taxonomy results.

Non-metric multidimensional scaling (NMDS) plots of worker (a), gyne or queen (b) and male (c) morphology. $\mathrm{HW}=$ head width, $\mathrm{HL}=$ head length, $\mathrm{SL}=$ scape length, $\mathrm{EL}=$ eye length;

$\mathrm{FL}=$ frontal lobes, $\mathrm{ML}=$ mesosoma length $\mathrm{PL}=$ petiole length, $\mathrm{PPL}=$ post-petiole length, $\mathrm{GL}=$ gaster length, $\mathrm{Cl}=$ cephalic index, $\mathrm{El}=$ eye index, $\mathrm{SI}=$ scape index, $\mathrm{FLI}=$ frontal lobe index, $\mathrm{WI}=$ waist length, $\mathrm{TL}=$ total length. $\mathrm{SL}$ is removed from worker NMDS (a) given its short vector and to show the M. mikromelanos sp. nov. type. Type specimen are indicated by a solid bold outline for both species, where the synonymized M. balboai (now M. zeteki; Weber 1958) is indicated with a dashed line, and paratypes are indicated by X's. (d) Worker tempo differences between $M$. zeteki and M. mikromelanos sp. nov. (e) Reconstructed multi-locus phylogeny indicates that the published genome from (Nygard et al. 2016; GCA_001594055.1) belongs to the new species, $M$. mikromelanos sp. nov.. Chemical chromatograms of $M$. mikromelanos sp. nov. (f) and M. zeteki (g) worker gasters indicating abundance differences of farnesenes: (1) E- $\beta$-farnesene, (2) (3Z,6E)- $\alpha$-farnesene, (3) (3E,6E)- $\alpha$-farnesene; with $M$. mikromelanos sp. nov. having a high abundance of (3) and low abundances (1) and (2), and M. zeteki having high a high abundance of (1) and low abundance (2) and (3). 

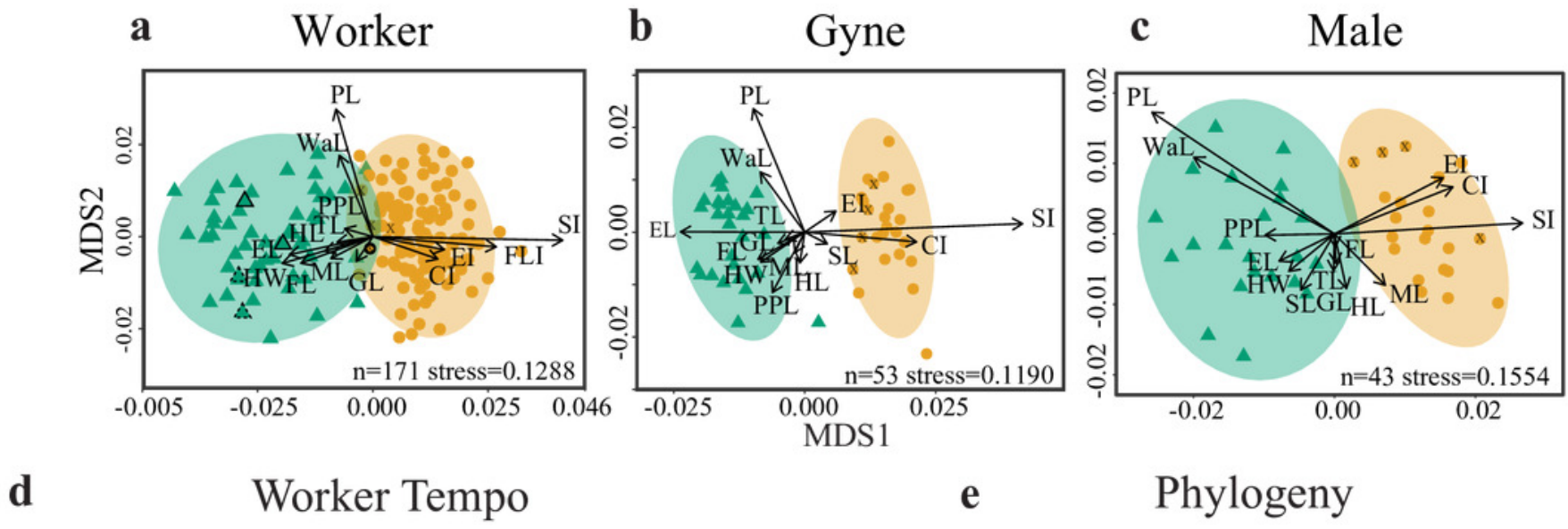

e Phylogeny

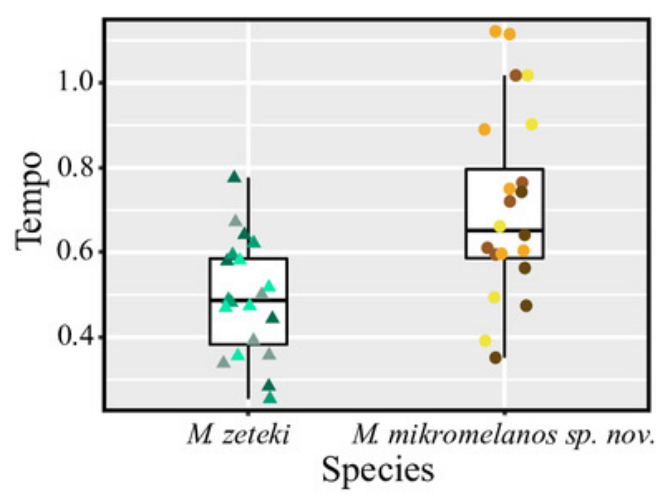

Colony

CRC170513-04

- CRC170513-10

- CRC1705115-05

- CRC170515-06

$\triangle$ CRC170519-01

$\triangle$ CRC170519-03

$\triangle$ MS170505-01

A RMMA100629-15

f M. mikromelanos sp. nov.

g Mycetomoellerius zeteki
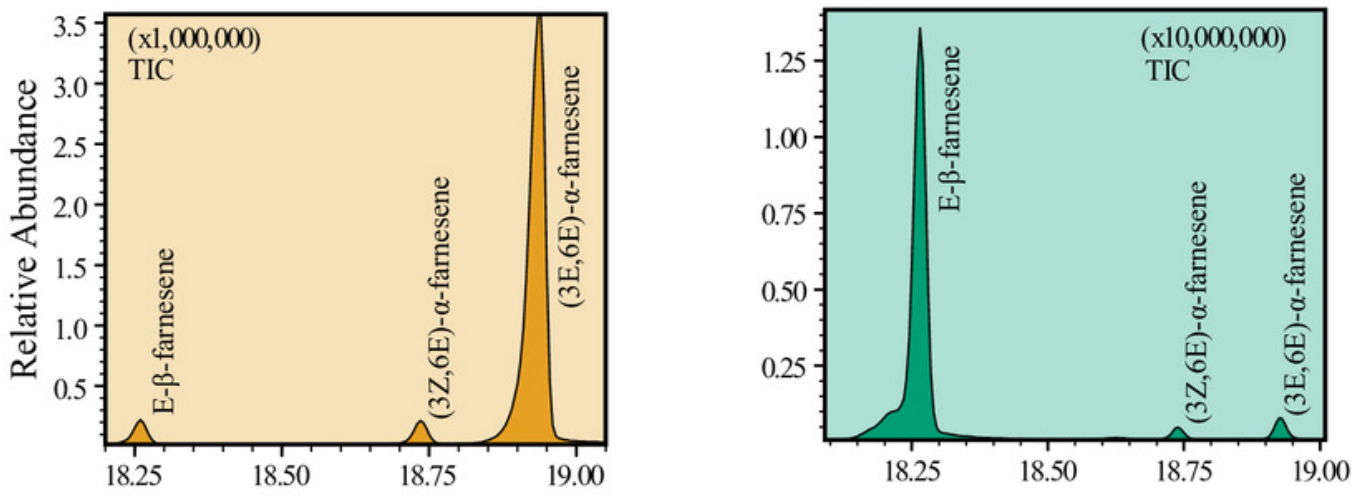

\section{Legend}

mikromelanos

sp. nov

zeteki

Retention Time 
Figure 2

Mycetomoellerius mikromelanos sp. nov. type (a - c) and gyne paratype (d - f) specimens.

(a) Worker profile. (b) Worker head frontal view; $F L=$ Frontal Lobe spine; $C E=$ Compound Eye; $D s c=$ Head capsule Disc; $S c p=$ Scape. (c) Dorsal worker view. (d) gyne paratype face view; $A R=$ Arcuate Ridge; $O S=$ Occipital Spine; Oc = Ocelli. (e) Gyne lateral view, $\mathrm{Ha}=$ Hamuli. (f) Gyne dorsal view Sclp = sculpturing. 


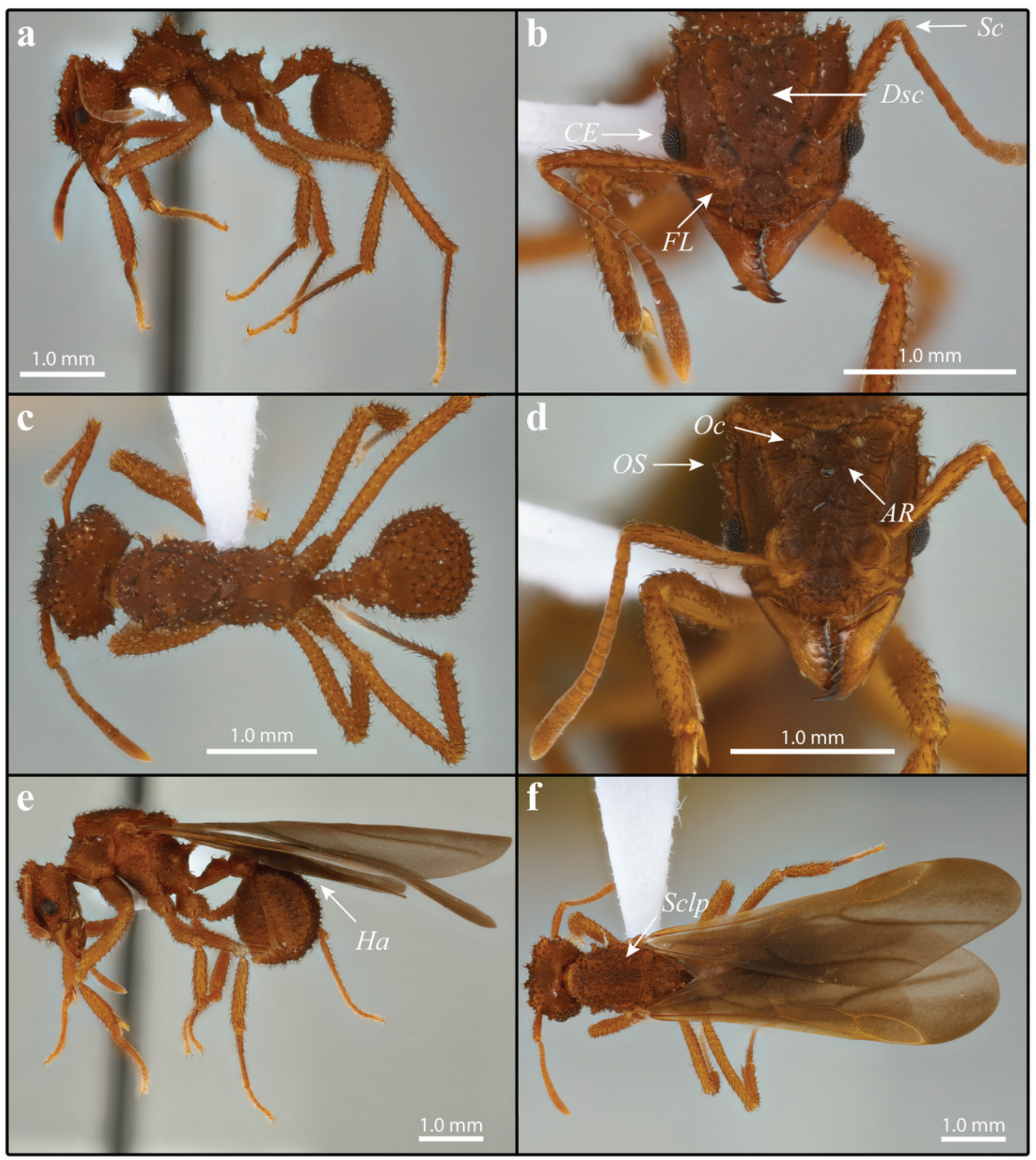


Figure 3

Mycetomoellerius mikromelanos sp. n. male paratype specimen.

(a) profile, lateral view, Sclp = Sculpturing; $P S=$ Propodeal Spine. (b) head frontal view $C l y=$ Clypeus impression corners; $O C=$ Oceli.

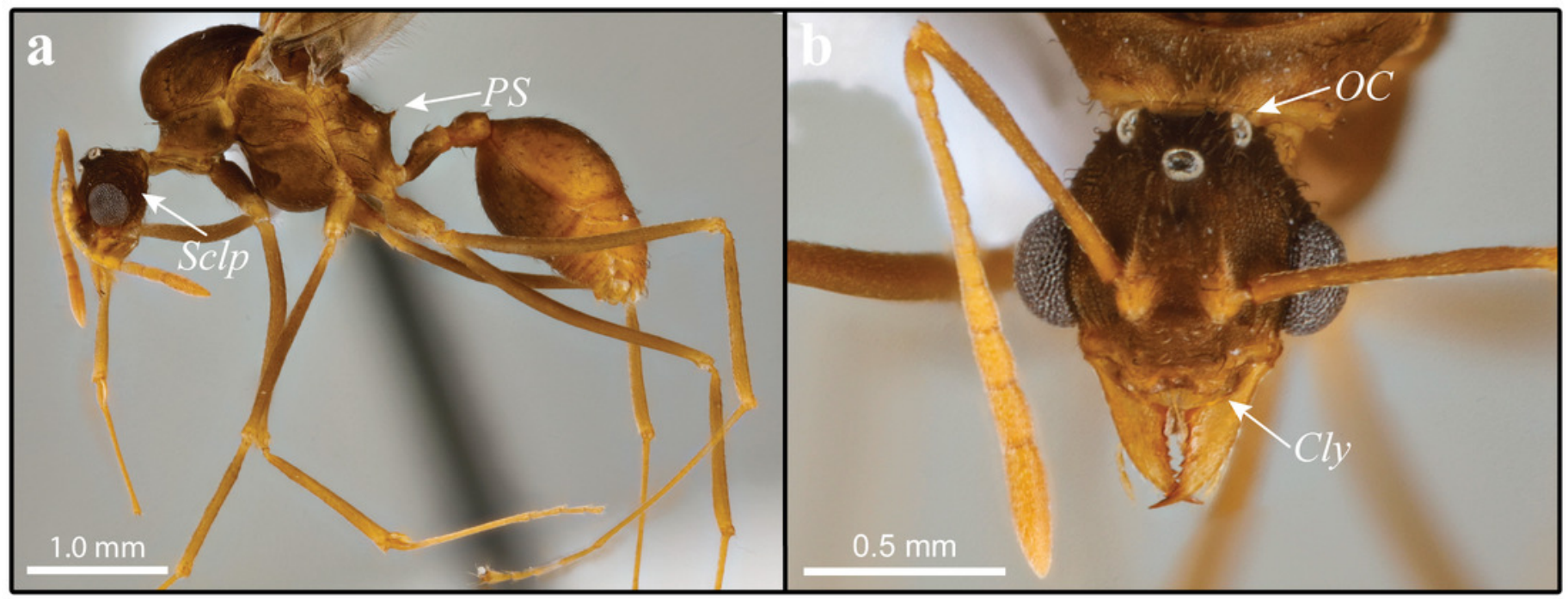


Figure 4

Mycetomoellerius zeteki worker (a - c) and gyne (d - f).

(a) Worker profile. (b) Worker head frontal view; $F L=$ Frontal Lobe spine; $C E=$ Compound Eye; $D s c=$ Head capsule Disc; Scp = Scape. (c) Dorsal worker view. (d) gyne paratype face view; $A R=$ Arcuate Ridge; $O S=$ Occipital Spine; Oc = Ocelli. (e) Gyne lateral view, $H a=$ Hamuli. (f) Gyne dorsal view Sclp = sculpturing. 


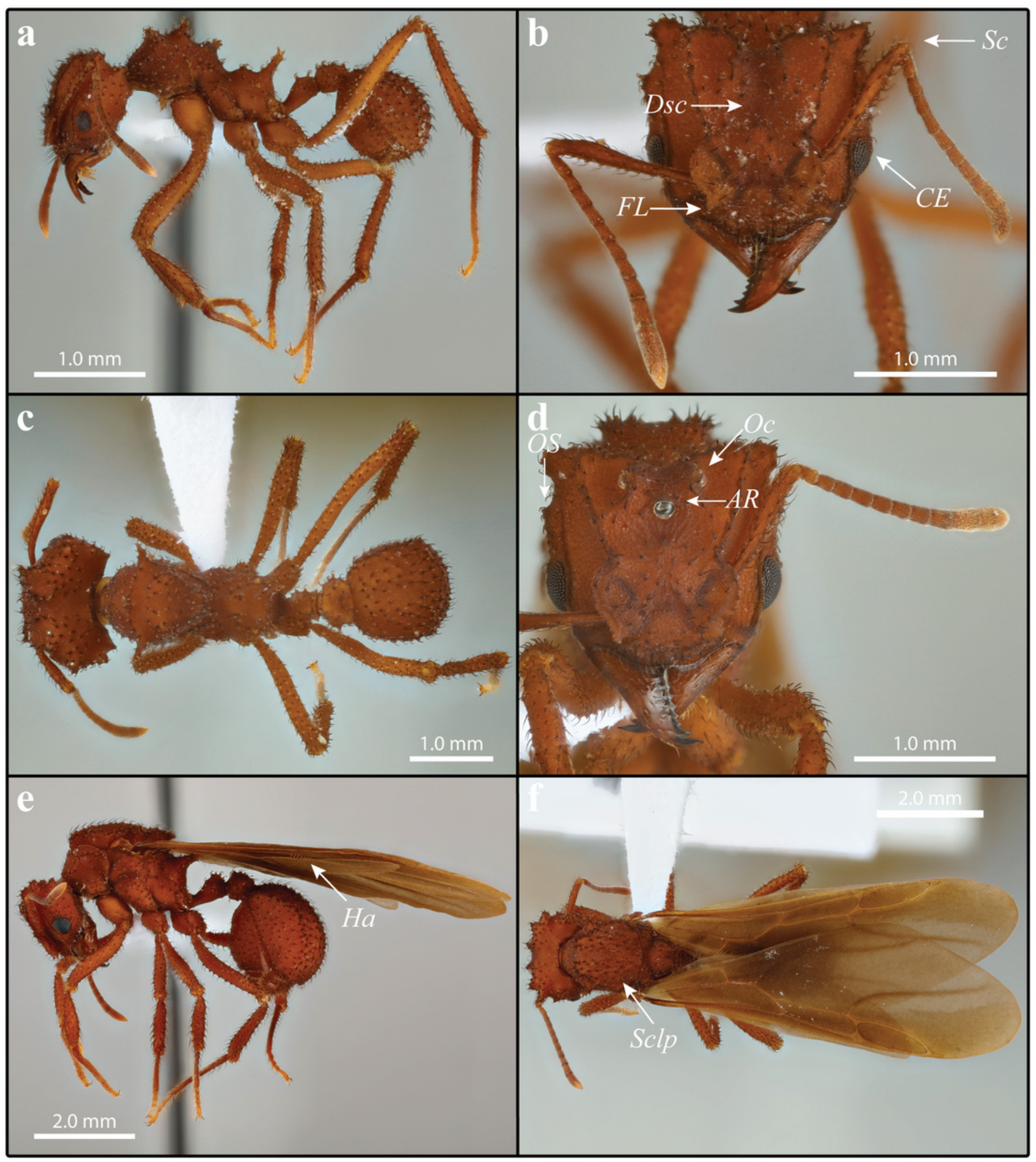


Figure 5

Mycetomoellerius zeteki male.

(a) profile, lateral view, $S c l p=$ Sculpturing; $P S=$ Propodeal Spine. (b) head frontal view $C l y=$ Clypeus impression corners; $O C=$ Oceli.

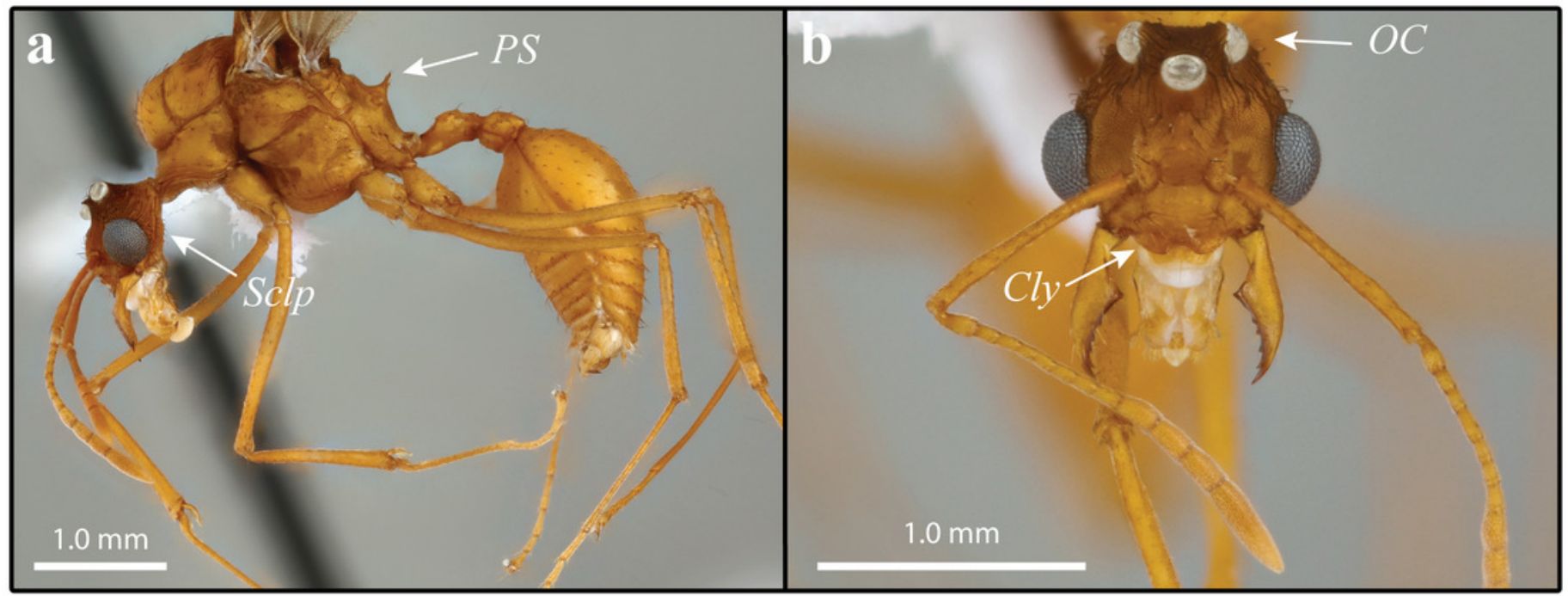

